\title{
Impact of the spatial distribution of active material on bifunctional hydrocracking
}

Juan I. Mirena ${ }^{\dagger}$, Joris W. Thybaut', Guy B. Marin', Johan A. Martens ${ }^{\S}$ and Vladimir V.

$$
\text { Galvita }^{\dagger *}
$$

${ }^{\dagger}$ Ghent University, Laboratory for Chemical Technology, Technologiepark 125, 9052 Ghent, Belgium, ${ }^{\S}$ KU Leuven, Center for Surface Chemistry and Catalysis, Celestijnenlaan 200F, 3001

Leuven, Belgium

\section{ABSTRACT}

Bifunctional catalysts are the preferred choice for hydrocracking processes. Ideal hydrocracking performance is defined by quasi-instantaneous (de)hydrogenation reactions over the metal sites and limited acid catalyzed side reactions, particularly the secondary cracking of desired products. Although their performance is heavily determined by the balance in activity between metal and acid sites, the spatial arrangement between both functions also holds a significant influence. Distance represents the simplest measure of the spatial distribution of active material. Various authors have explored the influence of the distance between sites, challenging the assumption that a minimal separation is necessary for ideal hydrocracking. Experimental evidence shows the important role of diffusion in the discussion of an intimacy criterion. The balance between site 
dispersion and mass transport properties within the porous catalyst can serve as a guideline in the tuning or design of ideal bifunctional catalysts.

\section{Introduction}

The energy sector continues to face a rising trend in global energy consumption. Present and future environmental regulations raise the challenge even further, since developed solutions need to comply with sustainability constraints. Despite the surging popularity of renewable energy sources such as wind or solar, fossil fuels are still expected to meet the majority of the global energy demand. Specifically, liquid fuels such as gasoline, diesel and jet fuel constitute the most prominent examples. ${ }^{1}$

Since the world's largest oil reserves consist of heavy or extra heavy crude oils, the oil industry has been moving in recent years towards refining lower quality, unconventional crudes. 2,3,4 These demand a greater degree of treatment and refining for producing better quality products, resulting in the production of significant amounts of petroleum residues and contaminants. ${ }^{5,6}$ As a consequence, to satisfy future fuel demands, it becomes crucial to employ heavier feedstocks in the production of liquid fuels with a high combustion efficiency and lower emissions of pollutants. ${ }^{4,7}$

The main goal of refining processes is to yield an optimal distribution of high value products with high hydrogen/carbon $(\mathrm{H} / \mathrm{C})$ ratios. ${ }^{5}$ Among the major upgrading methods, catalytic hydrocracking stands out significantly due to its large potential and flexibility for upgrading low value, heavy crude oils into lighter, higher quality and more valuable products such as gasoline, diesel or kerosene. ${ }^{8,9}$ Hydrocracking transforms long chain components into products with a lower molecular weight by splitting the side chains and saturating the aromatic and olefinic components in a hydrogen rich atmosphere. ${ }^{10}$ In particular, it becomes useful for treating the 
heavy byproducts of other upgrading processes such as catalytic cracking, delayed coking or visbreaking. ${ }^{11}$ One of the distinctive features of the hydrocracking process is the ability to isomerize alkanes to a large extent before cracking reactions become significant ${ }^{12}$. Branched alkane isomers such as those of $n-C_{5}$ and $n-C_{6}$ are usually employed for compensating octane number deficits in gasoline. ${ }^{13,14}$

Hydrocracking is preferably carried out over bifunctional catalysts with metal and acid functions. ${ }^{15,16}$ The performance of these bifunctional catalysts is strongly determined by factors related to the two types of sites, namely the balance between metal and acid functions and the physical separation between them. ${ }^{17,18}$ A proper understanding of how these properties can affect hydrocracking performance could provide guidelines for the tuning and design of bifunctional catalysts. Given the importance of hydrocracking in the general scheme of crude oil refining processes, the potential improvement of bifunctional catalysts represents an interesting opportunity. With environmental regulations becoming more strict, enhancing the performance of these processes only becomes more relevant since it poses a way to satisfy fuel demands while possibly reducing the environmental impact in a significant manner. In the present review, the work of different authors will be presented in the analysis of the effect of the balance between metal and acid sites, and the degree of proximity between metal and acid functions.

Bifunctional catalysts

Hydrotreating and hydrocracking processes are typically carried out over either monofunctional acid catalysts or bifunctional catalysts containing both metal and acid sites. ${ }^{16,19,20}$ These catalysts were first created for the catalytic reforming of naphtha and have been used in the industry since the 1950s. ${ }^{21}$ Currently, metal and acid bifunctional catalysts have become a basic element of many industrially relevant chemical processes for energy, environmental, and 
consumer based applications. ${ }^{22}$ Some of these processes include selective ring opening (an increase of the cetane number), hydroisomerization (an increase of the octane number), hydrocracking of heavy oils, reforming, and dewaxing. ${ }^{23,24,25}$ Compared to monofunctional acid alternatives, bifunctional catalysts prove to be more advantageous since they provide the opportunity to perform hydroconversion processes under milder conditions. For instance, at lower temperatures, due to the conversion of saturated hydrocarbons over the metal sites into unsaturated chains, which in turn are much more reactive. ${ }^{26}$ Furthermore, bifunctional catalysts are able to achieve broader product varieties and allow the product distribution to be more easily adjusted via the operating conditions. ${ }^{27}$ Other benefits include a generally much higher selectivity towards target products compared to monofunctional acid catalysts, together with a much slower deactivation via coking. ${ }^{28}$ Additionally, the production of petroleum products or fine chemicals, which entails several sequential reaction steps catalyzed by acid and metal sites, can be produced in one apparent step. ${ }^{29}$ As a result, bifunctional catalysts provide a significant reduction in energy consumption and waste generation. ${ }^{30}$

Even though the chosen composition of the catalyst depends on the desired product and the feedstock to be processed, common aspects can be observed for all bifunctional catalysts. ${ }^{31}$ The acid function is provided by Brønsted acid sites (BAS) for ensuring the skeletal isomerization and bond scission, while the active metal function for hydrogenation/dehydrogenation (HD/DHD) reactions can be given by finely dispersed noble metals in a reduced state, such as $\mathrm{Pt}$ or Pd. ${ }^{8,32,33,34}$ Among noble metals, Pt based catalysts have been confirmed to outperform Pd based catalysts, due to a higher hydrogenation capacity and metal dispersion values of the $\mathrm{Pt}$ phase. ${ }^{35}$ Traditional acidic supports for metal-acid bifunctional catalysts are zeolites (USY, Beta, Mordenite, ZSM-5, ZSM-22), silicoaluminophosphates (SAPO-11, SAPO-31, SAPO-41), 
mesoporous materials (MCM-41, Al/MCM-41) and amorphous oxides or a mixture of oxides (HF treated $\gamma-\mathrm{Al}_{2} \mathrm{O}_{3}, \mathrm{SiO}_{2}-\mathrm{Al}_{2} \mathrm{O}_{3}, \mathrm{ZrO}_{2} / \mathrm{SO}_{4}{ }^{2-}$ ). ${ }^{36,37}$ Zeolites are among the most promising support types due to their higher acid strength; low coking tendency; high resistance to contaminants such as aromatics, organic nitrogen, and sulfur; simple regeneration; and possible molecular shape selectivity. ${ }^{38}$ When combined with alumina, zeolites are frequently chosen to provide the acid function in the hydroconversion process because of their large variety of topologies, chemical compositions, and acido-basic properties. Consequently, zeolites are able to provide many different possibilities in the design of catalysts with desired activity and selectivity performance. ${ }^{39}$

The general mechanism of alkane hydroisomerization over bifunctional catalysts with Pt metal and zeolite acid sites is displayed in Figure 1. The seven steps that constitute such a mechanism are: (1) diffusion of a hydrocarbon molecule to metal site, (2) dehydrogenation of a hydrocarbon molecule on a metal site, (3) diffusion of the resultant olefin to an acid site, (4) isomerization and/or cracking of this olefin on acid sites, (5) diffusion of the products to a metal site, (6) hydrogenation of the reaction products, and (7) diffusion of the reaction product to the gas phase. 28

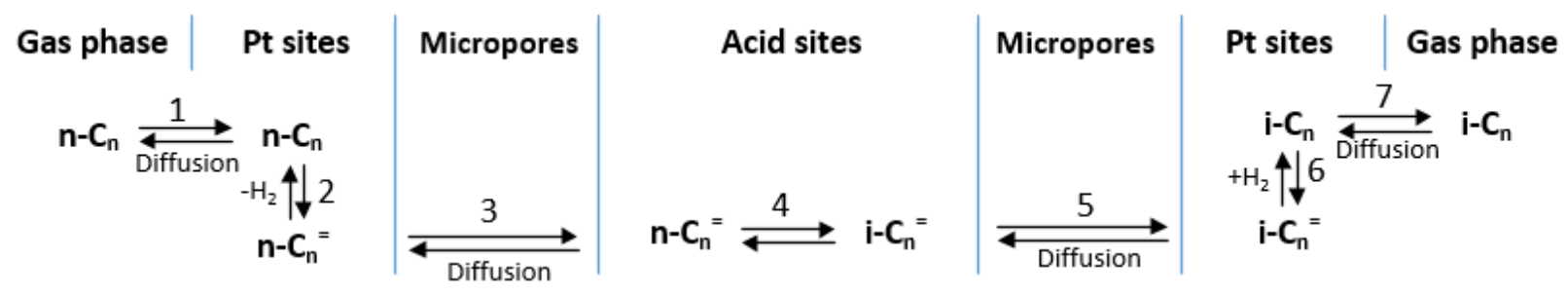

Figure 1. Scheme of alkane hydroisomerization over a bifunctional catalyst ${ }^{28}$ Adapted with permission from 28. Copyright 2013 Elsevier. 
The behavior of bifunctional catalysts depends on both the process conditions and the catalytic properties. The chain length of the reacting alkane and the operating conditions can affect the catalyst selectivity, activity, and stability. ${ }^{12,40}$ The main catalyst property that determines performance is the balance in activity between the metal and acid functions. However, the distance between them can also have a significant effect due to its direct impact on the olefin diffusion step of the reaction mechanism. ${ }^{41,42}$ In general, maximal isomerization activity, selectivity, and stability can only be obtained if the acid function is "well-balanced" by the metal function. ${ }^{27}$ This implies that the metal function is sufficiently active compared to the acid function and that an appropriate distance between metal and acid sites is ensured. ${ }^{31}$ The balance between the metal and acid functions is one of the core parameters in the development of a hydrocracking catalyst. By carefully balancing the metal and acid functions, the catalyst selectivity and activity can be adapted to a specific desired product, which is generally chosen to be either gasoline or a middle distillate fraction. ${ }^{43}$ An ideal bifunctional catalyst designed on a strong metal function provides flexibility in hydrocarbon conversion. ${ }^{22}$ Catalysts with a weaker cracking capacity and stronger HD/DHD functions tend to generate higher boiling products such as middle distillates, ${ }^{44}$ given that the incorporation of metal sites may reduce cracking reactions. ${ }^{45}$ On the other hand, in the case of a highly acidic catalyst, a distribution of products with lower boiling products is often attained due to the tendency for excessive cracking, thus decreasing the overall quality of the obtained fuels. ${ }^{22,46}$ There are multiple routes to make the metal/acid balance more beneficial, such as tuning the ratio between the total amount of exposed metal sites and the total amount of acid sites $\left(\mathrm{n}_{\mathrm{Me}} / \mathrm{n}_{\mathrm{A}}\right)$, adjusting the distance between both types of active sites, weakening the acid sites through the use of heteroatom implemented acid supports or 
reducing the acid density by adding non-acid species and improving the metal function through the formation of bimetallic sites. ${ }^{32,47,48}$

Effects of metal/acid balance on the catalytic performance of n-alkane hydroisomerization

Bifunctional catalysts employ a strong metal function together with a weak acid function to maximize the hydroisomerization of the n-alkanes, at the expense of cracking. ${ }^{37}$ It is stated that if the acid functions are more dominant than the metal functions, intermediate species on the acid sites will undergo cracking before the HD/DHD reactions on the metal sites. In the opposite case, the conversion of intermediates due to cracking will be limited due to the reduced number of acid sites. ${ }^{32}$ Additionally, the proximity between metal and acid sites serves as another condition that affects the isomerization yields of bifunctional catalysts. ${ }^{22}$ As a result, it is necessary to adjust ratios and distances between both active sites for improving hydroisomerization performance.

The effects of metal/acid balance can be experimentally investigated by modifying the ratio between metal and acid sites, $\mathrm{n}_{\mathrm{Me}} / \mathrm{n}_{\mathrm{A}}$. The activity, stability, and selectivity of the catalysts are governed by the $\mathrm{n}_{\mathrm{Me}} / \mathrm{n}_{\mathrm{A}}$ ratio. After a certain $\mathrm{n}_{\mathrm{Me}} / \mathrm{n}_{\mathrm{A}}$ value, where the activity of the metal function is sufficiently high compared to the activity of the acid function, both the activity and selectivity of the catalyst solely depend on the acid function. ${ }^{32}$ It has been shown that the ratelimiting reaction changes from HD/DHD over Pt sites to the skeletal rearrangement or cracking of olefinic intermediates over acid sites. ${ }^{41} \mathrm{~A}$ bifunctional catalyst can be considered to be ideal if it is able to establish quasi-equilibrium of the HD/DHD reactions, with the limited step involving the acid-catalyzed skeletal isomerization of alkene intermediates. ${ }^{49}$ The fundamental requirement for this ideal catalytic behavior is that the $\mathrm{n}_{\mathrm{Me}} / \mathrm{n}_{\mathrm{A}}$ ratio should be sufficiently high. Consequently, the turnover frequency (TOF) of these catalysts becomes high and sequential 
cracking reactions and coke formation are limited, which leads to improved selectivity, stability, and activity towards middle distillates. ${ }^{50}$

Numerous studies have specifically investigated the effect introduced by catalysts with a variations in their metal-acid site balance. Wei et al. ${ }^{51}$ sought to evaluate said effect by performing $\mathrm{n}$-hexadecane $\left(\mathrm{n}-\mathrm{C}_{16}\right)$ hydroisomerization in a fixed reactor bed set-up. The employed catalyst samples consisted of $\mathrm{Pd} / \mathrm{SAPO}-41$ with different $\mathrm{n}_{\mathrm{Me}} / \mathrm{n}_{\mathrm{A}}$ ratios, which were adjusted with different loadings of $\mathrm{Pd}$ during preparation and with various $\mathrm{SiO}_{2} / \mathrm{Al}_{2} \mathrm{O}_{3}$ ratios of the initial gel composition during the synthesis of SAPO-41. Thus, experiments centered around two sets of samples: the first one with varying ratios of $\mathrm{SiO}_{2} / \mathrm{Al}_{2} \mathrm{O}_{3}$ and a fixed $\mathrm{Pd}$ loading, and the second set with different $\mathrm{Pd}$ loadings and a defined $\mathrm{SiO}_{2} / \mathrm{Al}_{2} \mathrm{O}_{3}$ ratio. Wei et al ${ }^{51}$ found that, at a given temperature, samples prepared with different $\mathrm{SiO}_{2} / \mathrm{Al}_{2} \mathrm{O}_{3}$ ratios exhibited decreasing conversions of n-hexadecane as the amount of Brønsted acid sites in the samples was reduced. Although samples displayed an overall high yield of iso-hexadecanes, there were noticeable differences between the selectivity values towards iso-hexadecanes for all catalyst samples. Those with a lower amount of Brønsted acid sites showed a diminished isomer selectivity, likely caused by the cracking of branched alkenes. This was attributed to the low Brønsted acid density and Pd dispersion, which in turn would increase the distance between bifunctional pairs and raise the probability of cracking branched alkenes. On the other hand, samples with higher Brønsted acid densities and Pd dispersions would have metal and acid sites closer to each other, strengthening their synergetic effect and favoring the yield of iso-hexadecane.

Catalysts with varying Pd loadings exhibited a similar behavior in conversion with increasing temperature, however the sample with the highest Pd loading showed a clearly lower nhexadecane conversion. Based on these findings, Wei et al argued that catalyst activity is 
determined by the amount of accessible acid sites and an adequate $\mathrm{n}_{\mathrm{Me}} / \mathrm{n}_{\mathrm{A}}$ balance, despite lower Pd loadings. In contrast, the activity behavior of the sample with the highest Pd loading could be explained by the measured decrease in Brønsted acid sites, which in turn would cause the acid catalyzed steps to be rate-limiting. Furthermore, differences in iso-hexadecane selectivity were observed across the tested Pd loadings. Results show that the iso-hexadecane yields increased as the $\mathrm{n}_{\mathrm{Me}} / \mathrm{n}_{\mathrm{A}}$ ratio of the tested catalyst progressively increased from 0.06 to 0.58 . Wei et al suggested that more accessible metal sites and a higher $\mathrm{n}_{\mathrm{Me}} / \mathrm{n}_{\mathrm{A}}$ ratio are needed for quicker steps in both the dehydrogenation of n-hexadecane and the hydrogenation of intermediate alkenes. Moreover, a limited Pd loading would imply a higher average number of acid sites encountered by the olefinic intermediate as it diffuses between metal sites, thus reducing the selectivity towards iso-hexadecane. Nevertheless, compared to the sample with a metal-acid balance of 0.58 , a slight decrease in iso-hexadecane selectivity was observed for the catalyst sample with the highest Pd loading, despite its $\mathrm{n}_{\mathrm{Me}} / \mathrm{n}_{\mathrm{A}}$ ratio of 0.78 . This seemingly counterintuitive behavior could be explained by a longer residence time of intermediates inside the SAPO-41 zeolite. Textural characterization results suggest the possibility that the excess amount of Pd particles can partially block the pores of SAPO-41, thus hindering the diffusion of branched intermediates and resulting in a lower n-hexadecane conversion and a lower selectivity towards isohexadecane. Ultimately, Wei et al concluded that preserving the $\mathrm{n}_{\mathrm{Me}} / \mathrm{n}_{\mathrm{A}}$ ratio within an appropriate range is essential for attaining the desired catalytic behavior. Specifically for Pd/SAPO-41 catalysts, a $\mathrm{n}_{\mathrm{Me}} / \mathrm{n}_{\mathrm{A}}$ balance between 0.18 and 0.78 provided a sufficiently high activity and selectivity towards iso-alkane products. Below the lower limit, the cracking of isomer products was increased by the acid function. On the other hand, with $\mathrm{n}_{\mathrm{Me}} / \mathrm{n}_{\mathrm{A}}$ ratios exceeding 0.78 , the pores of SAPO-41 became partially blocked by Pd particles. ${ }^{51}$ 
Zhang et al. ${ }^{52}$ investigated the effect of bimetallic sites on the metal/acid balance by preparing a $\mathrm{Pd}-\mathrm{Ni}_{2} \mathrm{P} / \mathrm{SAPO}-31$ catalyst with 0.05 wt. $\% \mathrm{Pd}$ and 4 wt. $\% \mathrm{Ni}_{2} \mathrm{P}$ additions. The highest isomerization yield achieved by the addition of bimetallic sites amounted to $72 \%$, yet the isomer yield obtained by the same loadings of only $\mathrm{Pd}$ or $\mathrm{Ni}_{2} \mathrm{P}$ were 1.74 and 1.10 times lower, respectively. This significant improvement in performance induced by the bimetallic sites is mainly attributed to the effect of the enhanced metal/acid balance on the reaction mechanism. Figure 2 shows two possible mechanisms for $\mathrm{n}-\mathrm{C}_{16}$ hydroisomerization and hydrocracking over bifunctional catalysts with (a) low $n_{M e} / n_{A}$ values and (b) high values of $n_{M e} / n_{A}$.

(a)low values of $\mathbf{n M e} / \mathbf{n A}$
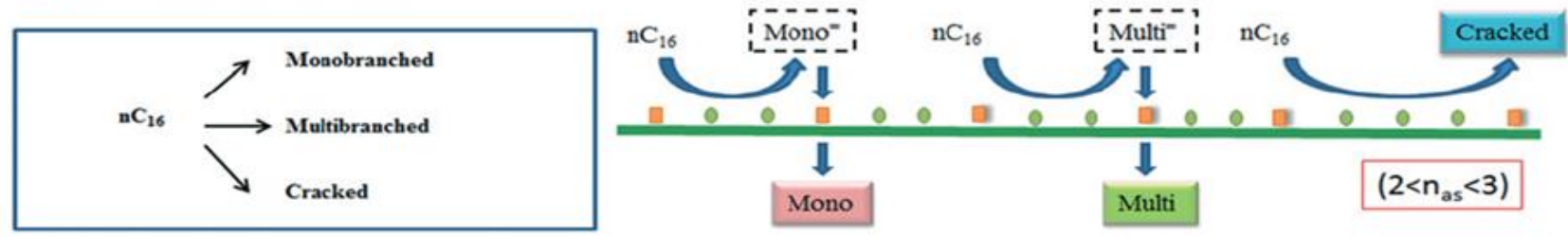

(b) High values of $\mathrm{nMe} / \mathrm{nA}$

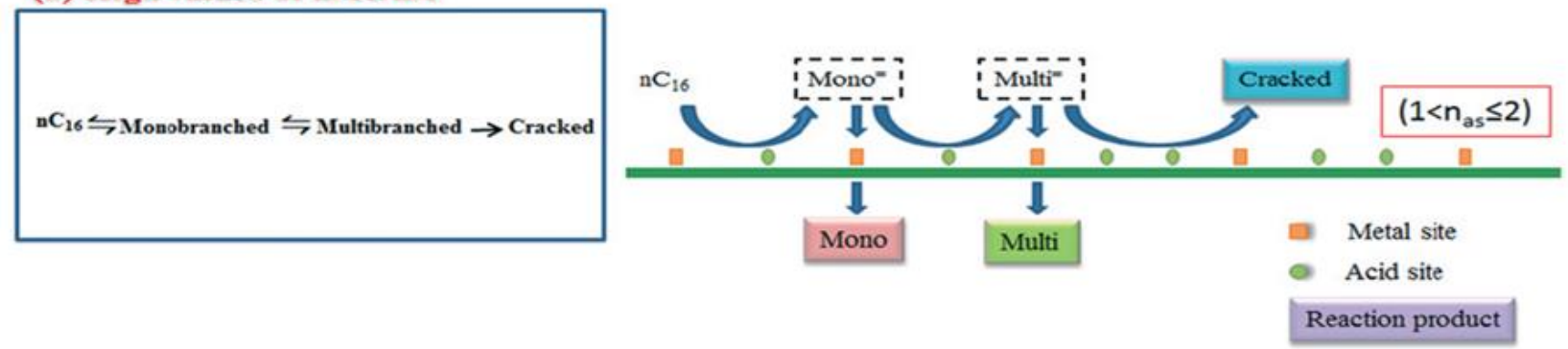

Figure 2. Scheme of $n-C_{16}$ hydroisomerization mechanisms over a bifunctional catalyst with (a) low values of $n_{M e} / n_{A}$ (b) high values of $n_{M e} / n_{A}{ }^{52}$ Reprinted with permission from 52. Copyright 2018 Royal Society of Chemistry.

The lowest $\mathrm{n}_{\mathrm{Me}} / \mathrm{n}_{\mathrm{A}}$ value was measured for Pd/SAPO-31 as 0.019 , whereas the metal/acid site balance for $\mathrm{Ni}_{2} \mathrm{P} / \mathrm{SAPO}-31$ and the bimetallic $\mathrm{Pd}-\mathrm{Ni}_{2} \mathrm{P} / \mathrm{SAPO}-31$ catalyst were measured as 0.055 and 0.115 , respectively. For the $\mathrm{Pd}$ based catalyst, the hydroisomerization of $\mathrm{n}-\mathrm{C}_{16}$ is presumed to have followed the parallel hydroisomerization mechanism shown in Figure 2a, with 
branched and cracking products being the primary products from the direct conversion of $n-C_{16}$. An estimate for the average number of acid sites that alkene intermediates can come in contact with during the diffusion step from the Pd sites $\left(\mathrm{n}_{\text {as }}\right)$ was made from the distribution of monobranched, multibranched and cracking products. In order to determine this value, a weighted sum was performed of the number of acid sites required to form each product type, with their corresponding weight fractions in the product stream. Monobranched products were assigned a single acid site. A value of 2.5 acid sites was assumed to account for all different multibranched isomers. On the other hand, the number of apparent acid sites required for cracking was estimated for each catalyst from the calculated number of cracking molecules per molecule of cracked $n-\mathrm{C}_{16} .{ }^{52}$ Since there is a lower amount of metallic sites on the Pd based catalyst, the number of acid sites that alkene intermediates can come in contact with during the diffusion step from the Pd sites $\left(\mathrm{n}_{\text {as }}\right)$ is between 2 and 3. Specifically, the determined $\mathrm{n}_{\text {as }}$ value for Pd/SAPO-31 was 2.24. Therefore, this "unbalanced" parallel hydroisomerization mechanism results in a higher possibility of consecutive isomerization or cracking of alkene intermediates. Figure $2 \mathrm{~b}$ describes the presumed mechanism over both $\mathrm{Ni}_{2} \mathrm{P} / \mathrm{SAPO}-31$ and $\mathrm{Pd}-\mathrm{Ni}_{2} \mathrm{P} / \mathrm{SAPO}-31$. Due to the increased amounts of accessible metal sites, the hydrogenation of intermediates is no longer the limiting step. Therefore, intermediates are likely to only encounter 1 or 2 acid sites between hydrogenation reactions. For the Ni based catalyst, a $\mathrm{n}_{\text {as }}$ value of 1.94 can serve as an explanation of the decreased formation of cracked products and multi-branched isomers compared to Pd/SAPO-31. A similar behavior was observed for the bimetallic catalyst, albeit with both a greater total isomer yield and a mono-branched product distribution. With a $\mathrm{n}_{\text {as }}$ value of 1.77 , the possibility of consecutive cracking/isomerization reactions becomes reduced even further, thus explaining the overall improved catalytic performance: alkene intermediates are 
able to easily undergo hydrogenation on the metal sites, favoring the formation of monobranched isomers over multi-branched isomers or cracked products. For these reasons, an increased $\mathrm{n}_{\mathrm{Me}} / \mathrm{n}_{\mathrm{A}}$ ratio could be considered as ideal for attaining a desirable performance from bifunctional catalysts. ${ }^{52}$

Alvarez et al. ${ }^{53}$ investigated the effect of different $\mathrm{n}_{\mathrm{Me}} / \mathrm{n}_{\mathrm{A}}$ values, increasing from 0.002 to 0.48 , for the hydroisomerization of $\mathrm{n}$-decane $\left(\mathrm{n}-\mathrm{C}_{10}\right)$ over a series of bifunctional catalysts based on $\mathrm{Pt} / \mathrm{HY}$. They attempted to understand the effect induced by the $\mathrm{n}_{\mathrm{Me}} / \mathrm{n}_{\mathrm{A}}$ balance on the hydroisomerization mechanism, catalytic activity, and stability. Figure 3 shows reaction networks for $\mathrm{n}-\mathrm{C}_{10}$ conversion at (a) low, (b) intermediate, and (c) high values of $\mathrm{n}_{\mathrm{Me}} / \mathrm{n}_{\mathrm{A}}{ }^{54}$. For catalysts with a $\mathrm{n}_{\mathrm{Me}} / \mathrm{n}_{\mathrm{A}}$ ratio below 0.03 , the initial activity and stability proved to be low and increased with higher $n_{M e} / n_{A}$ values. This result suggests that the HD/DHD reactions act as the rate-limiting for catalysts with lower loadings of metal sites. Under this condition, the average distance between two metallic sites becomes too large and thus the amount of acid sites encountered by the intermediate alkenes becomes accordingly excessive. Therefore, there is a major probability of multiple successive transformations of the alkenes before the HD/DHD reactions can occur on the metal sites. This implies that all i-decanes $\left(\mathrm{i}-\mathrm{C}_{10}\right)$ and cracking products were directly derived from $\mathrm{n}^{-\mathrm{C}_{10}}$ molecules, instead of being obtained from a consecutive reaction mechanism as shown in Figure 3c. For catalysts with $\mathrm{n}_{\mathrm{Me}} / \mathrm{n}_{\mathrm{A}}$ between 0.03 and 0.17 , their activity remained constant and the acid function became the rate-limiting step since there was an adequate balance of Pt and acid sites. However, the distance between two Pt sites still remained large for some of the n-alkene molecules, resulting in several consecutive conversions of $\mathrm{n}-\mathrm{C}_{10}$ into either the mono-branched or multi-branched isomers as shown in Figure $3 b$. For catalysts with a $\mathrm{n}_{\mathrm{Me}} / \mathrm{n}_{\mathrm{A}}$ ratio exceeding 0.17 , no deactivation due to coking was 
detected and $\mathrm{n}-\mathrm{C}_{10}$ molecules were converted sequentially into mono-branched $\mathrm{i}-\mathrm{C}_{10}$, then multibranched $\mathrm{i}-\mathrm{C}_{10}$ and finally into cracking products as shown in Figure 3c. For these catalysts, n$\mathrm{C}_{10}$ undergoes only one transformation prior to hydrogenation due to the lower number of encountered acid sites. Furthermore, experimental results showed that the maximum yield for i$\mathrm{C}_{10}$ products was achieved by a catalyst with a $\mathrm{n}_{\mathrm{Me}} / \mathrm{n}_{\mathrm{A}}$ ratio higher than $0.17 .{ }^{53}$ 


\section{a) low values of $\mathrm{nMe} / \mathrm{nA}$}
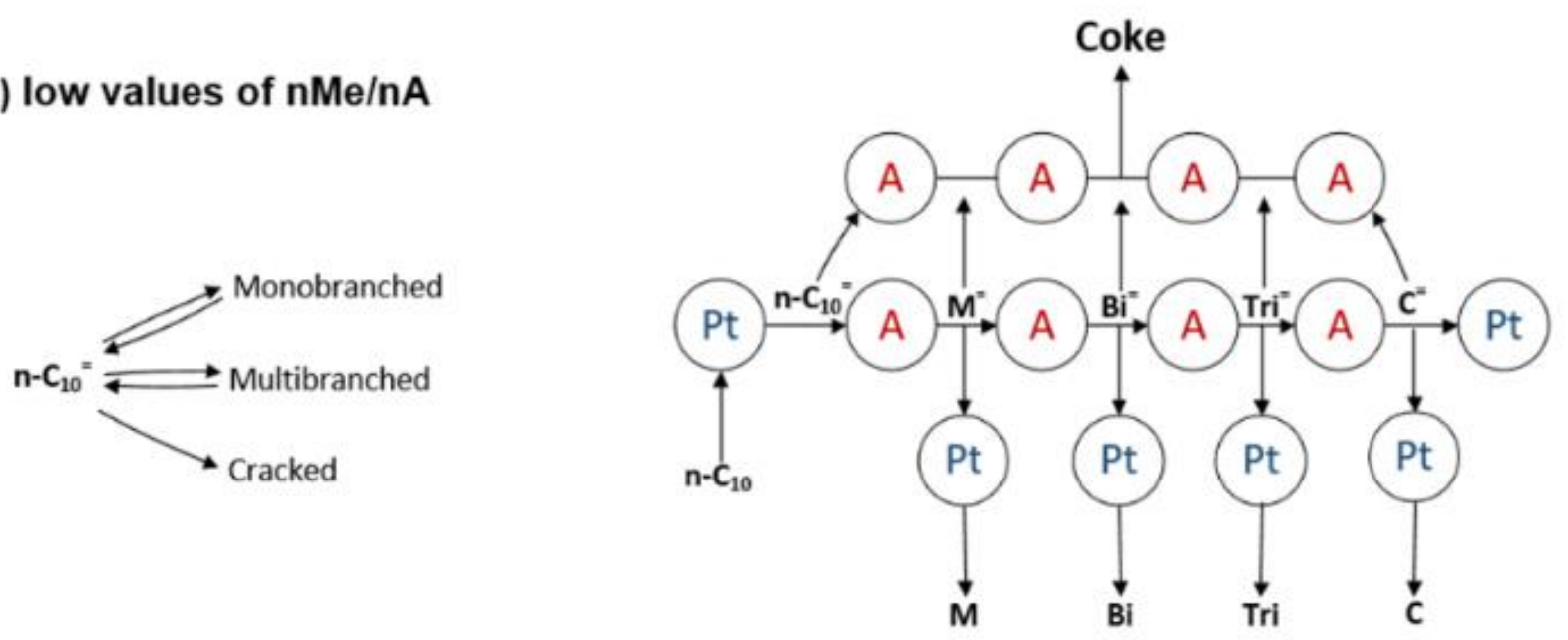

b) intermediate values of $\mathrm{nMe} / \mathrm{nA}$

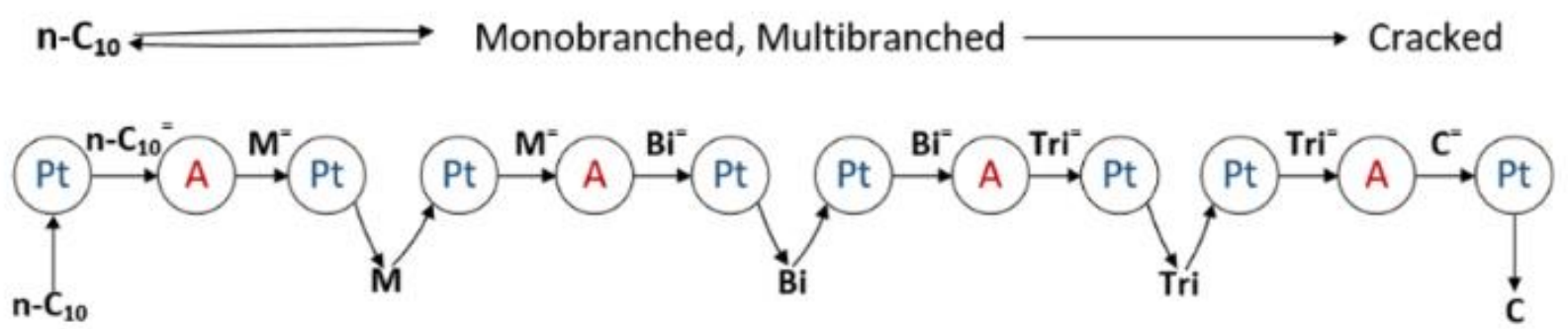

\section{c) high values of $\mathrm{nMe} / \mathrm{nA}$}

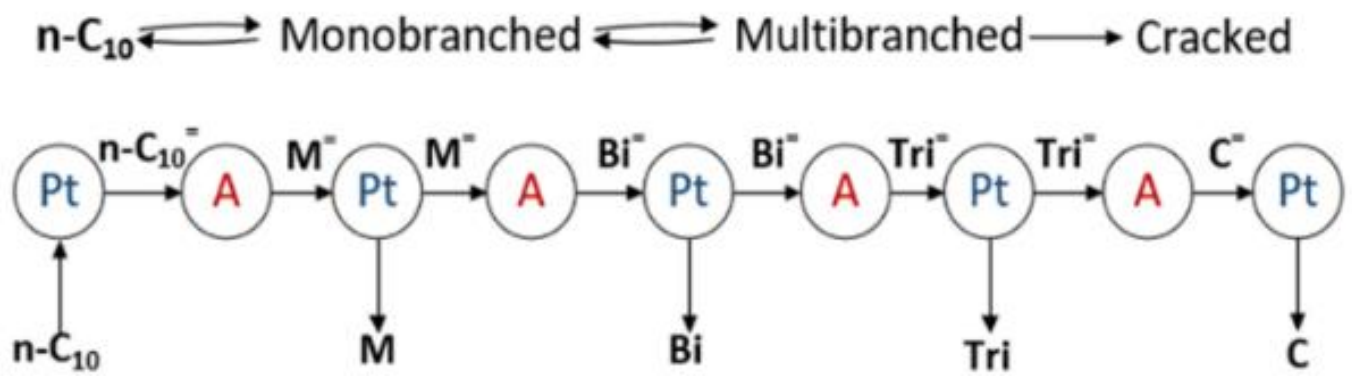

Figure 3. $n-C_{10}$ transformations over bifunctional catalysts at:(a) low values of $n_{M e} / n_{A}$, (b) intermediate values of $\mathrm{n}_{\mathrm{Me}} / \mathrm{n}_{\mathrm{A}}$, and (c) high values of $\mathrm{n}_{\mathrm{Me}} / \mathrm{n}_{\mathrm{A}}{ }^{54}$. Adapted with permission from 54 . Copyright 2005 Elsevier. 
Batalha et al. ${ }^{41}$ conducted a study with bifunctional catalysts containing Pt and HBEA as metal and acid functions to investigate the effect of the metal/acid balance on $n-C_{16}$. Three series of catalyst arrangements, shown in Figure 4a, were prepared and tested. In the first series (S1), metal functions were located on the outer surface of the HBEA zeolite crystals of $12.5 \mu \mathrm{m}$ with Pt loadings from 0.2 to 1.5 wt.\% (Pt/HBEA). The second (S2) and third (S3) series were obtained from an intimate mixture of $\mathrm{Pt}_{-} \mathrm{Al}_{2} \mathrm{O}_{3}$ and $\mathrm{HBEA}$ particles of $70 \mu \mathrm{m}$ and from a physical mixture of $\mathrm{Pt}-\mathrm{Al}_{2} \mathrm{O}_{3}$ and HBEA particles of $300 \mu \mathrm{m}$, respectively. The $\mathrm{S} 2$ and $\mathrm{S} 3$ bifunctional catalysts were labeled as PtA-HBEA (a-b), where a and b indicate the wt.\% of Pt$\mathrm{Al}_{2} \mathrm{O}_{3}$ and $\mathrm{HBEA}$, respectively. The temperature, total pressure, $\mathrm{H}_{2} / \mathrm{n}-\mathrm{C}_{16}$ molar ratio, and weight hourly space velocity (WHSV) were set to $220^{\circ} \mathrm{C}, 30 \mathrm{bar}, 20$, and 2-100 $\mathrm{h}^{-1}$, respectively.

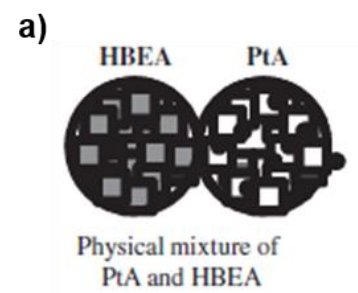

S3

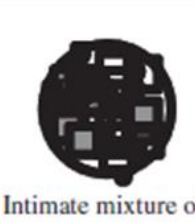

PtA and HBEA

S2

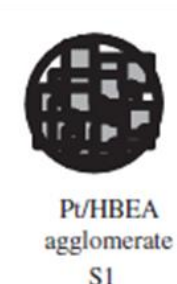

S1

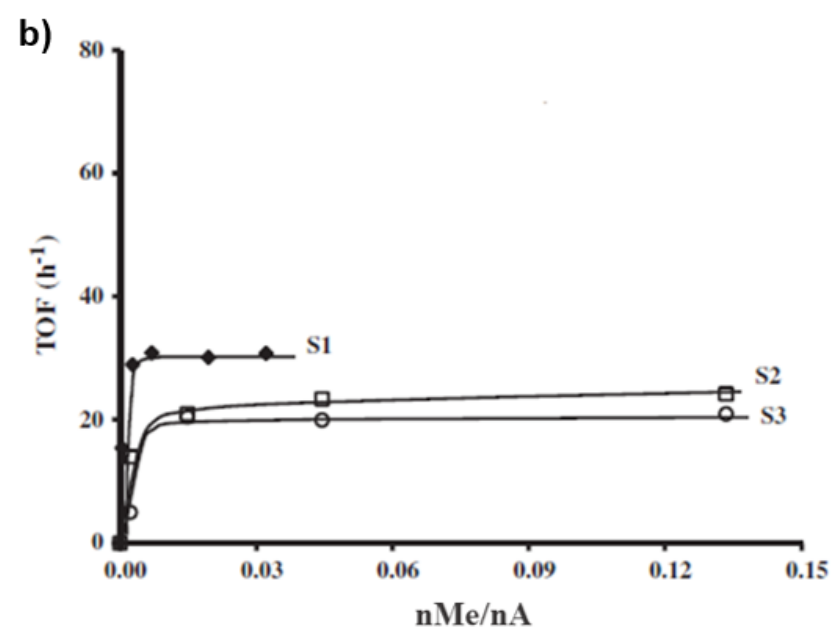

Figure 4. (a) Schematics of the series of bifunctional Pt-HBEA catalysts. S1: Metal functions located on the outer surface of the HBEA zeolite crystals. S2: Mixture of $\mathrm{Pt}_{-} \mathrm{Al}_{2} \mathrm{O}_{3}$ and HBEA 
particles $(70 \mu \mathrm{m})$. S3: Mixture of Pt- $\mathrm{Al}_{2} \mathrm{O}_{3}$ and HBEA particles $(300 \mu \mathrm{m})(\mathrm{b})$ Acid site TOF of the catalysts series (S1, S2 and S3) as a function of the $\mathrm{n}_{\mathrm{Me}} / \mathrm{n}_{\mathrm{A}}$ ratio ${ }^{41}$. Reprinted with permission from 41. Copyright 2013 Elsevier.

The ratio between the concentrations of accessible Pt atoms and acid sites, $\mathrm{n}_{\mathrm{Me}} / \mathrm{n}_{\mathrm{A}}$, was chosen to quantitatively describe the metal and acid balance. In Figure $4 b$, the TOF values versus $n_{M e} / n_{A}$ for all three catalyst series are shown. For all catalyst series, TOF increases with the $n_{M e} / n_{A}$ until it approaches a nearly constant behavior. For low $\mathrm{n}_{\mathrm{Me}} / \mathrm{n}_{\mathrm{A}}$ values, the HD/DHD reactions over the metal sites constitute the rate-limiting reaction for $\mathrm{n}_{-} \mathrm{C}_{16}$ hydroisomerization. For high $\mathrm{n}_{M e} / \mathrm{n}_{\mathrm{A}}$ values, the rearrangement of olefinic intermediates over the acid sites becomes the rate-limiting step. Thus, increasing the $\mathrm{n}_{\mathrm{Me}} / \mathrm{n}_{\mathrm{A}}$ ratio above a certain threshold does not have an effect on the TOF. Also, as seen in Figure 4b, it is noteworthy that the S1 series of catalysts exhibits the highest TOF for the same $\mathrm{n}_{\mathrm{Me}} / \mathrm{n}_{\mathrm{A}}$ values, followed by $\mathrm{S} 2$ and $\mathrm{S} 3$, suggesting higher activity with an increased degree of proximity between metal and acid functions.

Figure $5 \mathrm{a}$ and Figure $5 \mathrm{~b}$ display the yield weight ratios for cracking/isomer products $(\mathrm{C} / \mathrm{I})_{0}$ and multi/mono-branched isomers $(\mathrm{Bi} / \mathrm{M})$ as functions of the $\mathrm{n}_{\mathrm{Me}} / \mathrm{n}_{\mathrm{A}}$ ratios for the $\mathrm{S} 1, \mathrm{~S} 2$, and $\mathrm{S} 3$ catalysts. It can be seen that, with an increasing $\mathrm{n}_{\mathrm{Me}} / \mathrm{n}_{\mathrm{A}}$ value, all catalyst series become more selective toward to mono-branched isomers. Furthermore, both trends suggest that the bifunctional reaction process is not only affected by the $\mathrm{n}_{\mathrm{Me}} / \mathrm{n}_{\mathrm{A}}$ ratio, but also the separation between sites since the $\mathrm{C} / \mathrm{I}$ and $\mathrm{Bi} / \mathrm{M}$ ratios change with different site proximities. For the same $\mathrm{n}_{\mathrm{Me}} / \mathrm{n}_{\mathrm{A}}$ values, the C/I ratio strongly diminishes with an increased proximity between metal and acid sites. A similar behavior can also be observed for the Bi/M ratio, except for the values under a metal/acid site balance of 0.04 . 

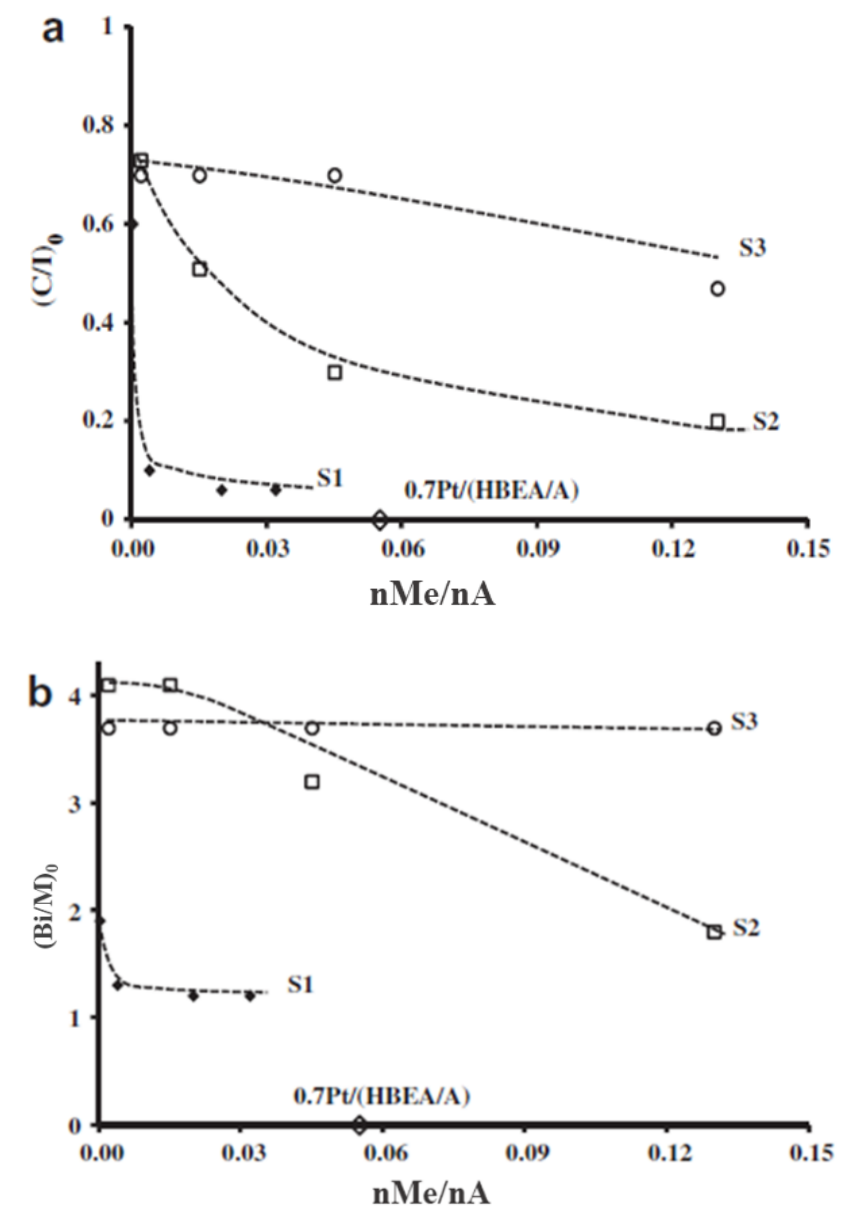

Figure 5. Initial values of the wt. $\%$ ratio of (a) $(C / I)_{0}$ and of (b) $(B i / M)_{0}$ versus $n_{M e} / n_{A}{ }^{41}$. Reprinted with permission from 41. Copyright 2013 Elsevier.

Since there is not a direct and accurate technique to properly evaluate the proximity between both sites, the degree of proximity was quantified by the number of acid sites $\left(\mathrm{n}_{\text {as }}\right)$ encountered by intermediates between $\mathrm{HD} / \mathrm{DHD}$ reactions ${ }^{55}$. Such values were determined using a method based on the product distribution. The product weight fractions were employed in the weighted sum of the estimated number of acid sites responsible for the formation of monobranched, multibranched and cracked products. A single acid site was considered for transforming nalkanes into monobranched products. In the case of multibranched products, an approximate value of 2.5 sites was employed since the ratio of di- and tribranched isomers approached 1. 
Moreover, a value of 5 acid sites was assumed to be involved in the transformation of $n$-alkanes into cracked products ${ }^{41}$. As mentioned previously, $\mathrm{n}_{\mathrm{Me}} / \mathrm{n}_{\mathrm{A}}$ values should be sufficiently high such that the acid catalyzed reactions can be rate-limiting. Moreover, the $\mathrm{n}_{\text {as }}$ value should be close to 1 in order to only catalyze one skeletal rearrangement or cracking reaction of the olefinic intermediates as these diffuse between metallic site pairs. It can be seen in Figure 6a that, for all S3 catalysts, the $n_{\text {as }}$ values are close to 3 ; whereas for the $S 1$ and $S 2$ catalysts, the $n_{\text {as }}$ values decrease with rising $n_{M e} / n_{A}$ values. For the same $n_{M e} / n_{A}$ values, the $S 1$ catalysts have the lowest $\mathrm{n}_{\mathrm{as}}$ values and their diminishing trend is significantly more pronounced than the profiles for both S2 and S3. In Figure 6b, as the distance between two active sites increases from $0.01 \mu \mathrm{m}$ to 300 $\mu \mathrm{m}, \mathrm{n}_{\text {as }}$ changes from 1 to 3.05 and the yield of $\mathrm{i}-\mathrm{C}_{16}$ decreases from $80 \%$ to $20 \%$. Consequently, if the distance between both types of sites is shorter, a lower $n_{\text {as }}$ value will be reached. As a result of this study, it was found that the balance between the metal and acid functions and their proximity are the main parameters that determine the rate and selectivity of $\mathrm{n}-\mathrm{C}_{16}$ hydroisomerization. Moreover, the distance between acid and metal sites shows a stronger influence on catalytic performance compared to the $\mathrm{n}_{\mathrm{Me}} / \mathrm{n}_{\mathrm{A}}$ ratio. ${ }^{41}$ 

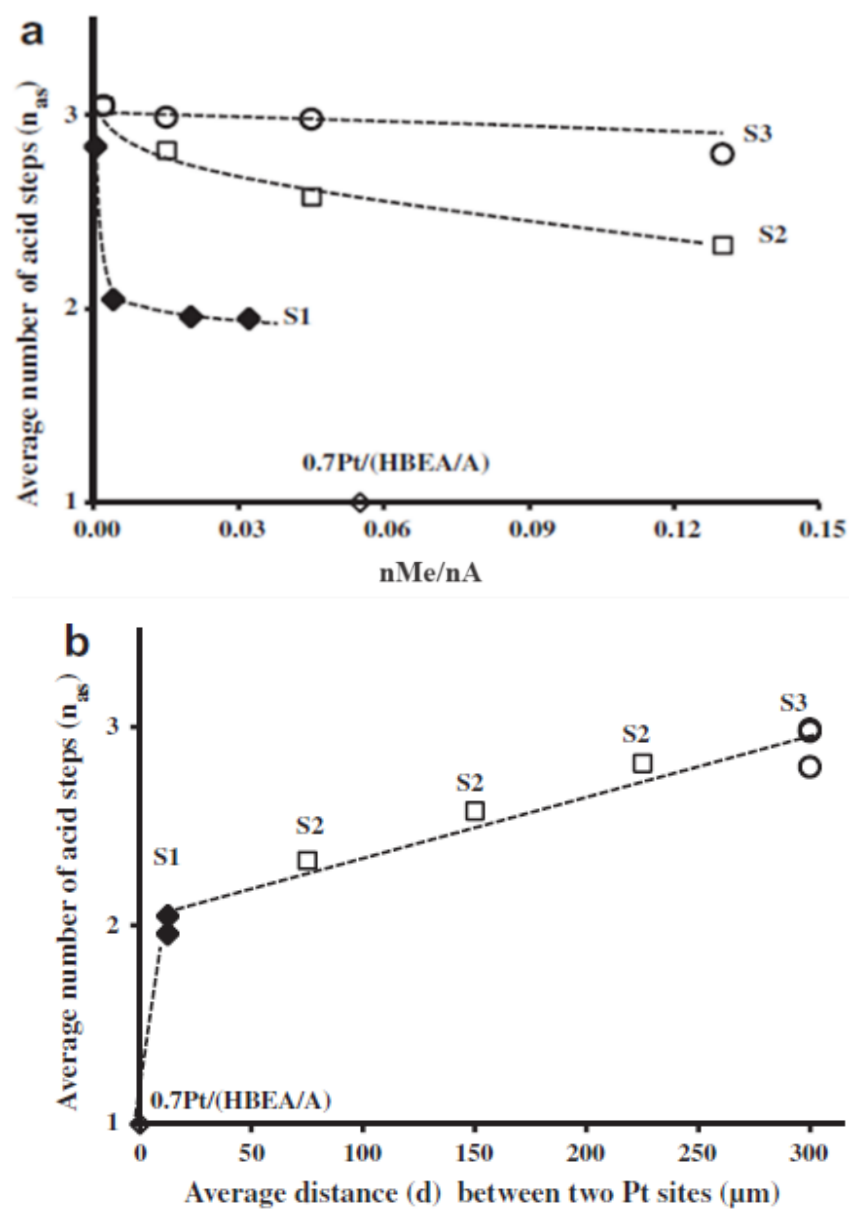

Figure 6. Average number of acid steps $\left(n_{a s}\right)$ involved in the transformation of one $n-C_{16}$ versus (a) the $\mathrm{n}_{\mathrm{Me}} / \mathrm{n}_{\mathrm{A}}$ ratio and (b) the distance $(\mathrm{d}, \mu \mathrm{m})$ between two Pt sites ${ }^{41}$. Reprinted with permission from 41. Copyright 2013 Elsevier.

As a general conclusion, the aforementioned studies suggest that the average number of acid sites in contact with alkene intermediates during hydroisomerization should be close to 1 in order to obtain a single reaction on the acid sites. For this condition to occur, the $\mathrm{n}_{\mathrm{Me}} / \mathrm{n}_{\mathrm{A}}$ ratio would need to be sufficiently high. However, an excessive amount of metal sites would potentially block pores with metal particles and consequently reduce n-alkane conversion while increasing the cost of catalyst preparation. Thus, the possibility of an optimal range of $n_{M e} / n_{A}$ values for achieving an improved performance of bifunctional catalysts should be investigated further. 
Lastly, the balance of metal/acid sites is not the only relevant parameter defining catalytic behavior, since the proximities between bifunctional sites prove to have a significant effect as well.

Effects of the distance between metal and acid sites on the performance of bifunctional catalysts

The distance between metal and acid sites has also been a relevant research topic in the field due to its impact on the performance of bifunctional catalysts. A well-balanced catalyst is described as ideal if it also satisfies a proper proximity between metal and acid sites. ${ }^{18}$ Numerous authors have explored this intimacy criterion throughout the years, sometimes coming to conflicting conclusions. Traditionally, it has been stated that the metal and acid sites should lie in sufficient proximity to guarantee that the diffusion of olefinic intermediates does not limit the kinetics. ${ }^{56}$ The seminal work of Weisz ${ }^{17}$ was the first to introduce the notion of such a criterion. In his experiments, $\mathrm{Pt} / \mathrm{C}$ or $\mathrm{Pt} / \mathrm{SiO}_{2}$ metal site particles and acidic silica-alumina particles with the same size were prepared separately to investigate the effect of the intersite distance. Due to the limitation of techniques at that time, the distance between metal and acid sites was tuned by varying the size of the aforementioned particles for $n$-heptane $\left(n-C_{7}\right)$ hydroisomerization. It was found that the yields of $i$-heptane $\left(i-C_{7}\right)$ over catalysts with smaller component particle size, such as 5 or $70 \mu \mathrm{m}$, were higher than those of catalysts with $1000 \mu \mathrm{m}$ particle size. This experimental trend was consistent with Weisz's intimacy requirement. If there is a large distance between sites, hydroisomerization becomes further controlled by the longer diffusion of the olefinic intermediates, resulting in a decline of the catalytic activity. Simultaneously, secondary reactions over the acid sites become more likely, leading to a rise in the production of both cracked products and coke. It was found that the particle size of catalysts should be below $100 \mu \mathrm{m}$ to 
overcome diffusion limitations and approach the catalytic performance behavior of silicaalumina impregnated with Pt. ${ }^{17}$

Since then, the intimacy criterion has typically been assumed to involve the closest possible proximity between metal and acid sites. ${ }^{50,33,41}$ Such an arrangement would in turn optimize catalytic activity and selectivity towards isomer products. However, some recent studies have revived the discussion on the optimal distance between both catalyst functions for improved efficiency. ${ }^{57,22}$ Several researchers have investigated the influence of intersite distances within the nanometer and atomic scales employing enhanced deposition methods.

Samad et al. ${ }^{22}$ studied the proximity criterion using a bifunctional catalyst containing $\mathrm{Pt}$ distributed over an acidic silica-alumina support for $\mathrm{n}-\mathrm{C}_{7}$ isomerization with different degrees of proximity between the metal and acid sites. The Pt sites were electrostatically deposited onto silica with cationic tetraamine $\left(\mathrm{Pt}\left(\mathrm{NH}_{3}\right)_{4}{ }^{2+}\right)$ precursors $(\mathrm{PTA})$ at high $\mathrm{pH}$ values. Conversely, $\mathrm{Pt}$ sites were placed onto alumina through the use of anionic hexachloride $\left(\mathrm{PtCI}_{6}{ }^{2-}\right) \mathrm{Pt}$ precursors (CPA) at low $\mathrm{pH}$ values. With the help of both precursors, two different degrees of proximity between both functions were achieved. For the catalysts obtained by electrostatic adsorption of PTA at a $\mathrm{pH}$ of 11 (PTA-11), the metal and acid sites were located within the atomic scale, which was the closest proximity. Additionally, another catalyst prepared by dry impregnation (DI) of PTA over an Al-Si support (PTA-DI), showed the same proximity level as PTA-11. A nanometer scale proximity between both functions was achieved through the deposition of CPA onto alumina at $\mathrm{pH} 4$ (CPA-4). The micrometer scale proximity between metal and acid sites was obtained by physical mixtures (PM) of metal and acid functions. Lastly, a series of catalysts considered the addition of quartz wool as an inert layer to further separate the metal and acid functions within the millimeter scale. These were labeled as L\#, where \# indicates the separation 
distance in $\mathrm{mm}$. The four series of catalysts with bifunctional proximities within the atomic, nanometer, micrometer, and millimeter scales are summarized in Figure $7 .^{22}$
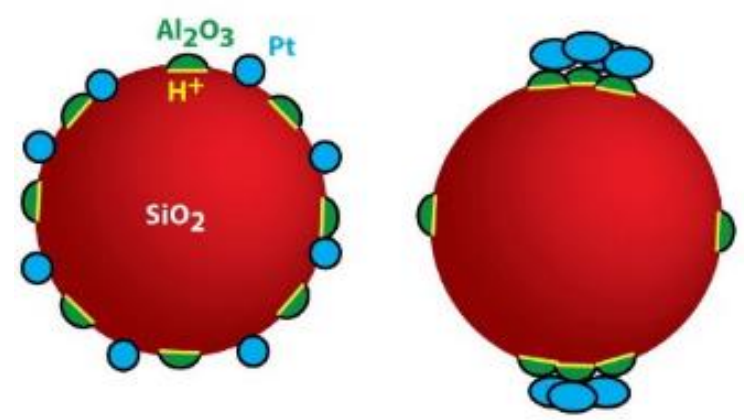

PTA-11, PTA-DI (atomic-scale)

CPA-4

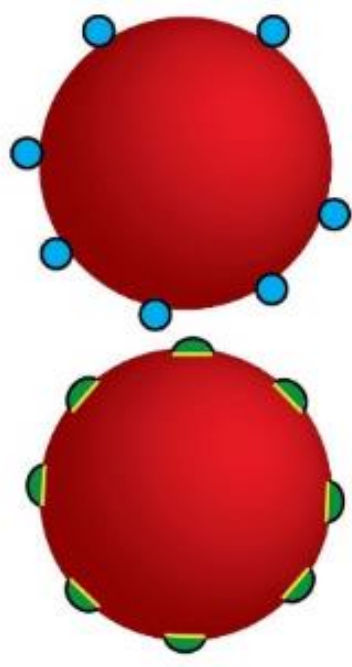

PM

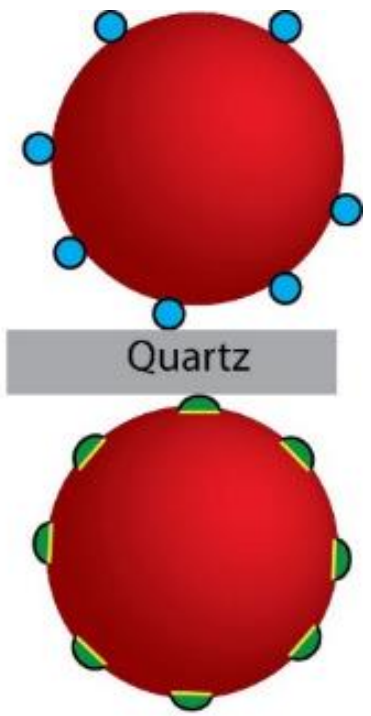

L-1

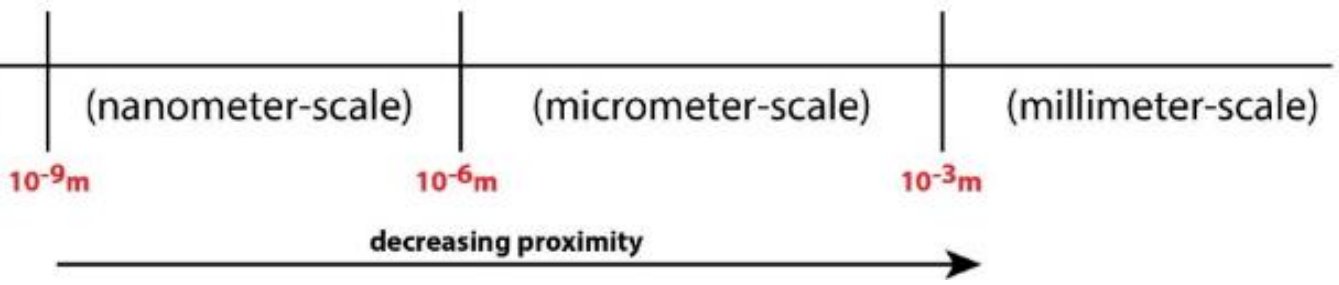

Figure 7. Catalyst configurations with varying degrees of intimacy between active sites. Red and blue spheres respectively indicate silica particles and Pt sites. Green/yellow spheres represent acidic alumina $^{22}$. Reprinted with permission from 22. Copyright 2016 Elsevier.

Isomerization of $\mathrm{n}-\mathrm{C}_{7}$ was performed in a $\mathrm{U}$-shaped flow-type, fixed bed, quartz tube reactor, operated at a temperature of $350^{\circ} \mathrm{C}$ and a pressure of $1 \mathrm{~atm}$. Figure 8 shows the performance of the PM and L-\# catalysts together with a schematic representation of the reactor packing. Pt/R_Si and Al_Si are the metal-only and acid-only monofunctional configurations and were tested separately to serve as a reference for comparison. Total catalyst mass for the 1:1 PM and layered configurations was $0.4 \mathrm{~g}$, with equal mass $(\sim 0.2 \mathrm{~g})$ of acid and metal components. Results showed that if the distance between two active sites increases to the millimeter scale, 
catalysts approximately behave as monofunctional catalysts and their performance will quickly decline due to the fact that alkene intermediates cannot diffuse very far between both active sites. Thus, a large distance between sites prevents the isomerization reaction from taking place. All of the layered catalysts, from L1 to L3, showed a degree of deactivation and selectivity similar to the monofunctional catalyst (Pt/R_Si) as displayed in Figure $8 \mathrm{~b}$. On the other hand, catalytic performance improved significantly for the PM catalyst compared to the others since its metal and acid sites were mixed and located more closely together. It can also be seen in Figure $8 \mathrm{~b}$ that for the PM catalyst $\mathrm{i}-\mathrm{C}_{7}$ selectivity was greatly enhanced, whereas cracking and cyclic products decreased remarkably. Figure 8a shows that the initial and final activity of the PM catalyst was notably higher than the others.
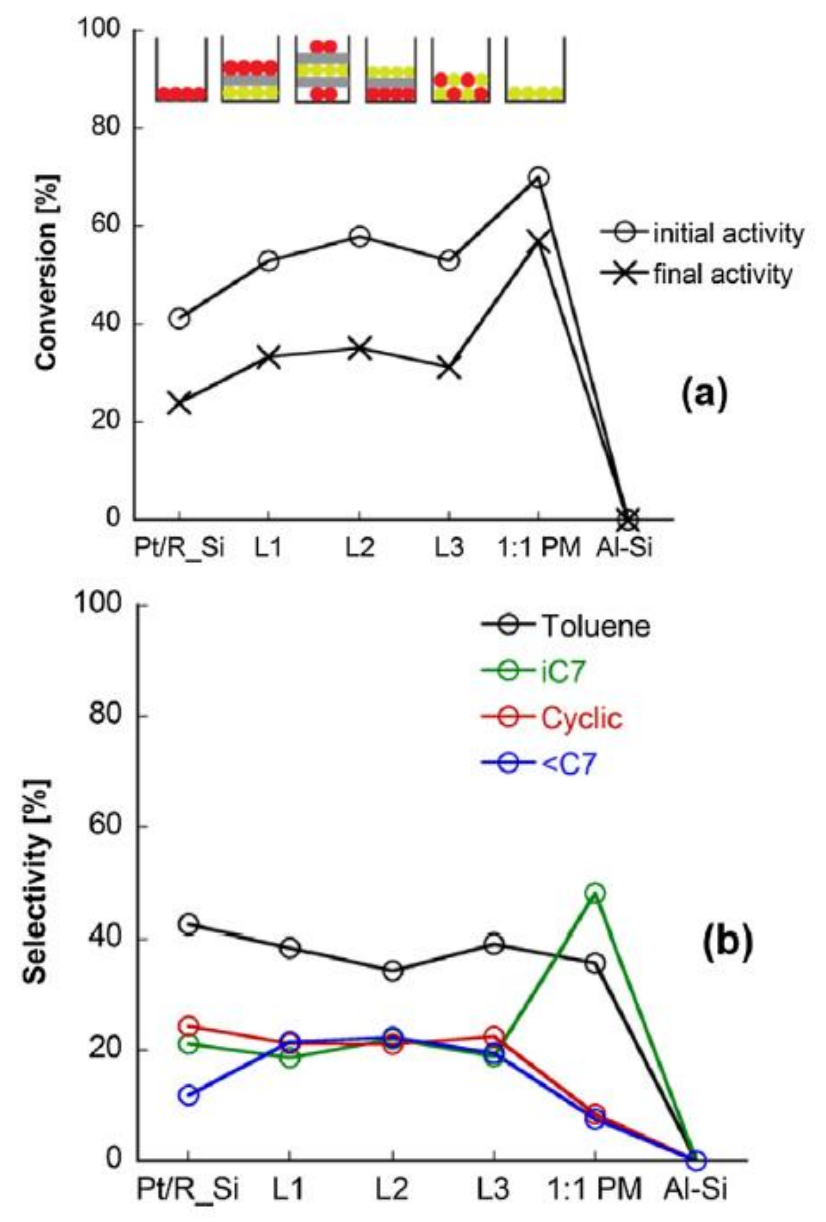
Figure 8. (a) $n-C_{7}$ conversion and (b) product distributions at approx. $22 \%$ conversion for various configurations of Pt/R_Si and SIRAL 80 (Al-Si) based catalysts. Yellow circles, red circles, and gray strips symbolize SIRAL 80 as an acidic support, Pt/R_Si and a layer of quartz wool, respectively ${ }^{22}$. Reprinted with permission from 22. Copyright 2016 Elsevier.

Figure 9 a displays the product distribution at approximately $22 \%$ conversion after a time on stream (TOS) of $18 \mathrm{~h}$ for the different sets of monofunctional and bifunctional catalysts. The metal-only catalyst, Pt/R_Si, prepared by non-acidic silica shows good selectivity toward i-C 7 . Also, as shown in Figure 8, the initial and final conversions of $\mathrm{n}-\mathrm{C}_{7}$ over this metal-only catalyst were found to be $41 \%$ and $24 \%$, respectively, indicating remarkable activity towards $\mathrm{i}-\mathrm{C}_{7}$. The other metal-only catalyst Pt/R_Al prepared without silica also displays notable selectivity towards $\mathrm{i}-\mathrm{C}_{7}$. On the other hand, the acid-only monofunctional Al-Si catalyst exhibits no activity under the tested conditions. In Figure $9 \mathrm{~b}$ the bifunctional, weakly acidic Al-LSi 99 support was used, so PTA-11 and CPA-4 catalysts show quite similar performance to the Pt/R_Si metal-only monofunctional catalyst. Lastly, the PTA-DI catalyst shows no activity owing to its lower fractional metal dispersion (3\%), compared to the PTA-11 and CPA-4 catalysts, and the low acidity of the Al-LSi 99 support. In Figure 9c and Figure 9d, the product distributions for the bifunctional, strongly acidic, silica-rich Al-HSi 97 and SIRAL supported catalysts are shown. It can be seen that the catalyst prepared by CPA-4 (nanometer scale proximity) exhibits notably higher selectivity toward $\mathrm{i}-\mathrm{C}_{7}$ compared to the catalysts prepared by PTA-11 and PTA-DI (atomic scale proximity). As a result, this study found that the greatest bifunctionality is achieved by proximities between metal and acid in the nanometer and micrometer scales sites instead of an even smaller separation within the atomic scale. ${ }^{22}$ This conclusion, in principle, challenges 
the assumption that a minimal proximity between metal and acid functions is always required for an ideal hydrocracking behavior.
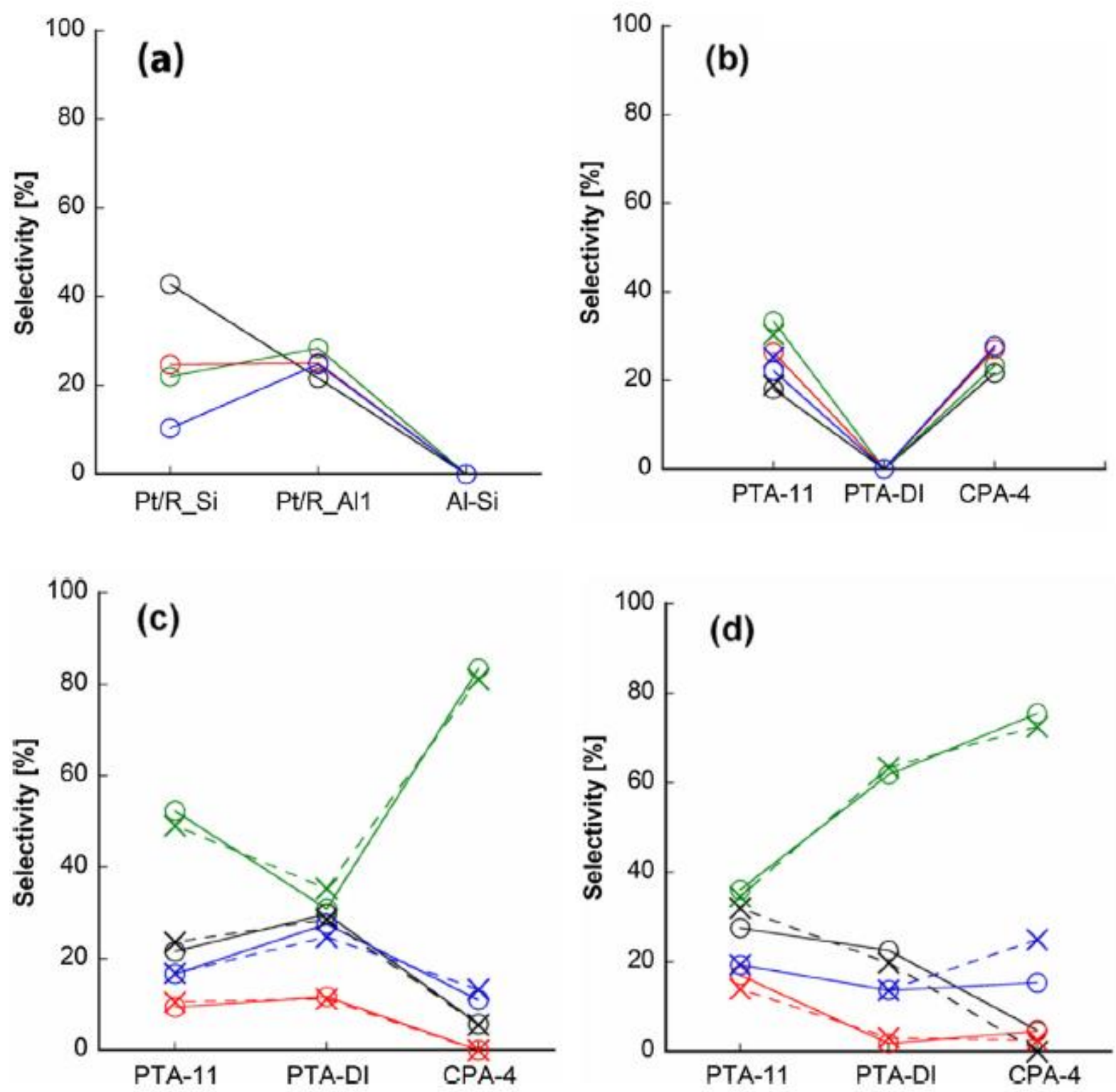

Figure 9. Product distribution at $22 \%$ conversion of (a) monofunctional Pt/R_Si (metal), Pt/R_Al1 and Al-Si (acidic SIRAL 80) and bifunctional (b) Al-LSi 99, (c) Al-HSi 97 and (d) SIRAL 80 supported catalysts. (i-C $\mathrm{C}_{7}$ : green, toluene: black, cyclic: red, $<\mathrm{C}_{7}$ : blue, o-solid lines: 0.7 wt.\% catalyst, and x-dashed lines: 0.4 wt.\% catalyst) ${ }^{22}$. Reprinted with permission from 22 . Copyright 2016 Elsevier. 
In another study conducted by Gutierrez-Acebo et al. ${ }^{56}$, two series of bifunctional catalysts with different $\mathrm{n}_{\mathrm{Me}} / \mathrm{n}_{\mathrm{A}}$ ratios and different metal to acid site proximities were prepared to test the hydroconversion of ethylcyclohexane (ECH) over Pt/EU-1 zeolite catalysts. The EU-1 zeolite and Pt particles were selected as the acid and metal functions, respectively. The metal and acid site balance was tuned by only changing the amount of metal sites. The distance between the metal and acid sites was adjusted by depositing Pt particles either on the zeolite (Pt/HEU-1) or the alumina support $\left(\mathrm{Pt} / \mathrm{Al}_{2} \mathrm{O}_{3}\right)$. Then a mixture containing $80 \%$ of $\mathrm{Al}_{2} \mathrm{O}_{3}$ and $20 \%$ of Pt/HEU-1 was prepared mechanically, attaining a nanometer scale proximity between bifunctional sites (PtHEU-1/ $/ \mathrm{Al}_{2} \mathrm{O}_{3}$ ). In contrast, a mixture of $80 \%$ of $\mathrm{Pt} / \mathrm{Al}_{2} \mathrm{O}_{3}$ and $20 \%$ of HEU-1 was prepared mechanically, resulting in a microscale proximity of metal and acid sites ( $\left.\mathrm{Pt}-\mathrm{Al}_{2} \mathrm{O}_{3} / \mathrm{HEU}-1\right)$. The hydroconversion of ECH was performed in a steel, fixed bed reactor at temperatures between 230 and $330^{\circ} \mathrm{C}$, a pressure of $10 \mathrm{bar}, \mathrm{H}_{2} / \mathrm{ECH}$ ratio of 40 , and a weight hourly space velocity (WHSV) of 4 grams of ECH per gram of catalyst per hour.

Figure 10 and Figure 11 display the isomerization and cracking selectivities as a function of the ECH conversion for the Pt-HEU-1/ $/ \mathrm{Al}_{2} \mathrm{O}_{3}$ and Pt- $\mathrm{Al}_{2} \mathrm{O}_{3} / \mathrm{HEU}-1$ catalyst mixtures, each with different Pt loadings (wt.\%). Since the acidity remains the same for all catalysts, a higher Pt content increases the $\mathrm{n}_{\mathrm{Me}} / \mathrm{n}_{\mathrm{A}}$ ratio. It can be seen that the Pt- $\mathrm{Al}_{2} \mathrm{O}_{3} / \mathrm{HEU}-1$ and Pt-HEU-1/Al $\mathrm{O}_{3}$ mixtures with $1 \%$ and $2.3 \% \mathrm{Pt}$ loadings yield more isomers and less cracked products compared to the other catalysts due to their relatively higher $\mathrm{n}_{\mathrm{Me}} / \mathrm{n}_{\mathrm{A}}$ ratio. ${ }^{56}$ 

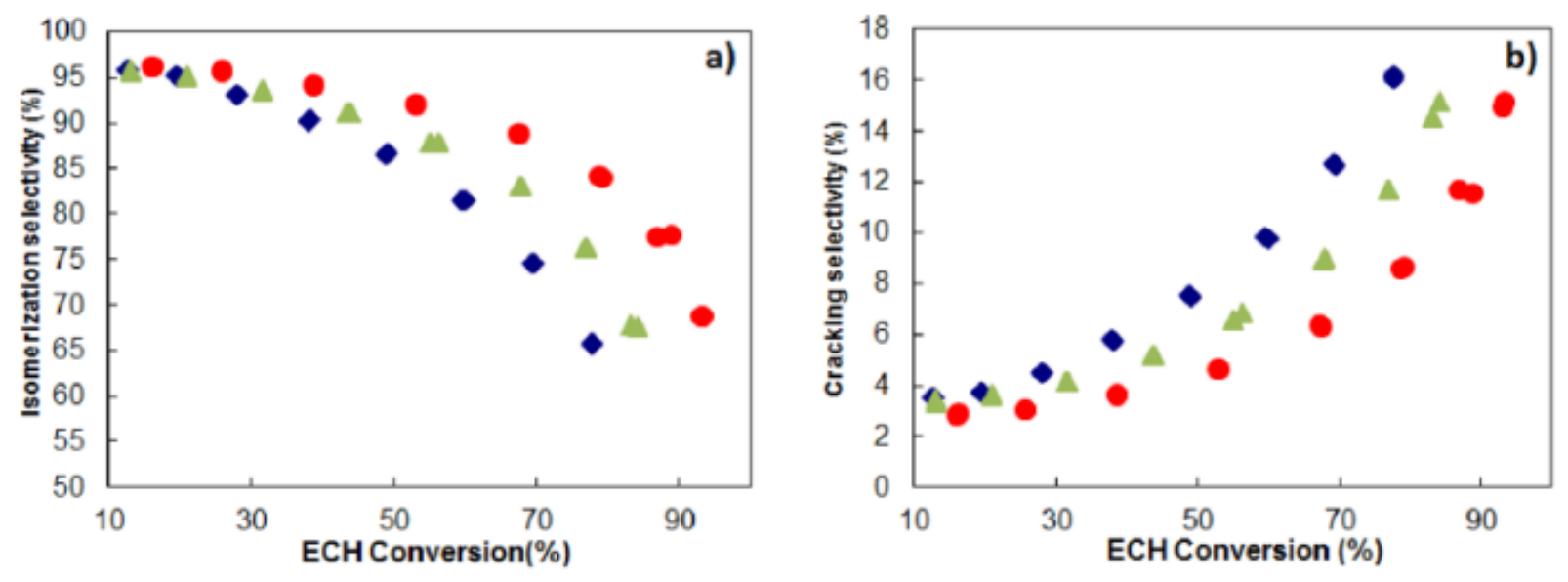

\section{$\bullet \quad 0.5 \% \mathrm{Pt} \quad \triangle \quad 0.8 \% \mathrm{Pt} \quad \bullet 1 \% \mathrm{Pt}$}

Figure 10. Evolution of the selectivity versus ECH conversion for Pt-HEU-1/ $\mathrm{Al}_{2} \mathrm{O}_{3}$ catalysts: (a) towards isomerization products and (b) towards cracking products ${ }^{56}$. Reprinted with permission from 56. Copyright 2018 American Chemical Society.
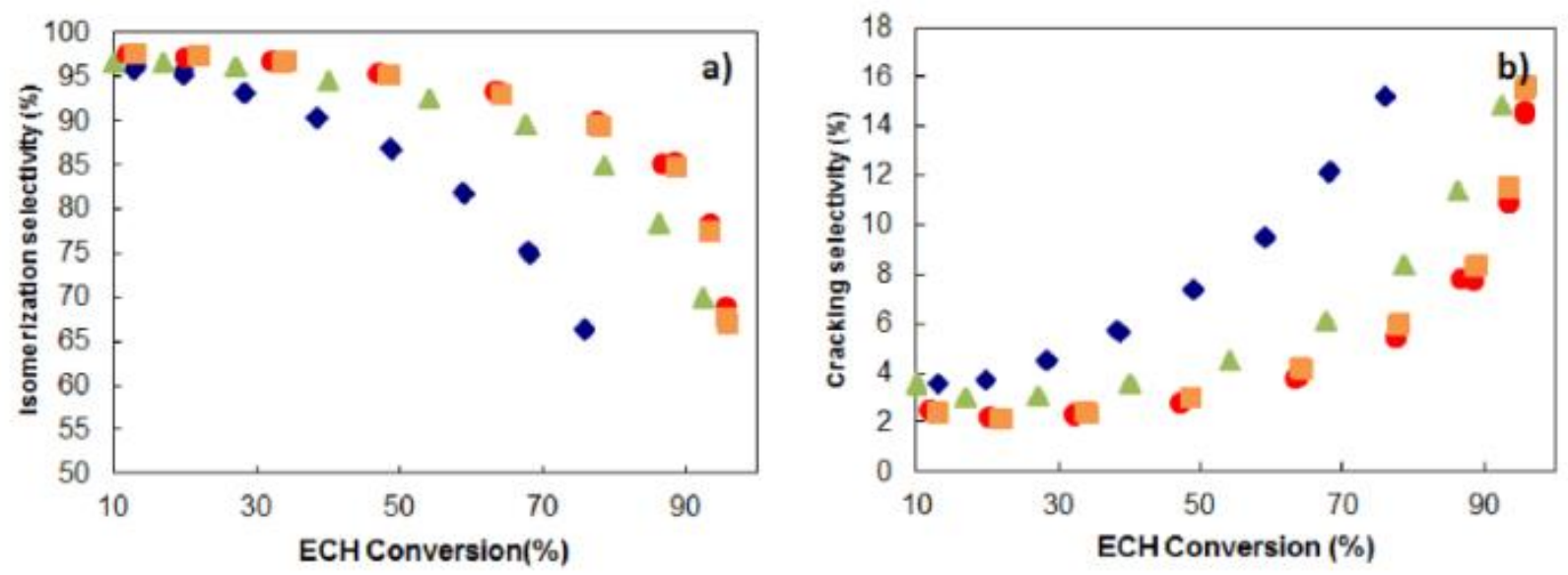

\begin{tabular}{|lllll|}
\hline $0.1 \% \mathrm{Pt}$ & $\Delta \quad 0.2 \% \mathrm{Pt}$ & $-1 \% \mathrm{Pt}$ & $2.3 \% \mathrm{Pt}$ \\
\hline
\end{tabular}

Figure 11. Evolution of the selectivity versus $\mathrm{ECH}$ conversion for the $\mathrm{Pt}-\mathrm{Al}_{2} \mathrm{O}_{3} / \mathrm{HEU}-1$ catalysts: (a) towards isomerization products and (b) towards cracking products ${ }^{56}$. Reprinted with permission from 56. Copyright 2018 American Chemical Society. 
Figure 12 shows the TOF and the maximal i-cyclo- $\mathrm{C}_{8}$ isomerization yields of the various PtHEU-1/ $\mathrm{Al}_{2} \mathrm{O}_{3}$ and Pt- $\mathrm{Al}_{2} \mathrm{O}_{3} / \mathrm{HEU}-1$ mixtures in terms of their $\mathrm{n}_{\mathrm{Me}} / \mathrm{n}_{\mathrm{A}}$ ratios. Results show that similar activities and selectivities are achieved for $\mathrm{Pt}-\mathrm{HEU}-1 / \mathrm{Al}_{2} \mathrm{O}_{3}$ and $\mathrm{Pt}-\mathrm{Al}_{2} \mathrm{O}_{3} / \mathrm{HEU}-1$ at the same $\mathrm{n}_{\mathrm{Me}} / \mathrm{n}_{\mathrm{A}}$ values, suggesting that nanoscale and microscale distances have similar effects on catalyst performance. Consequently, it appeared that transport limitations did not occur in the micropores of the zeolite at the tested operating conditions. As a result, it was concluded that the $\mathrm{n}_{\mathrm{Me}} / \mathrm{n}_{\mathrm{A}}$ ratio was considerably more influential than the tested distances between metal and acid functions. ${ }^{56}$ In comparison to the work of Samad et al. ${ }^{22}$, this work serves as an example of possible experimental issues that can prevent an adequate assessment of the impact on catalyst performance caused by the separation between metal and acid sites. A more refined experimental design is required to specifically identify and analyze the influence of site placement and transport limitations on site intimacy.
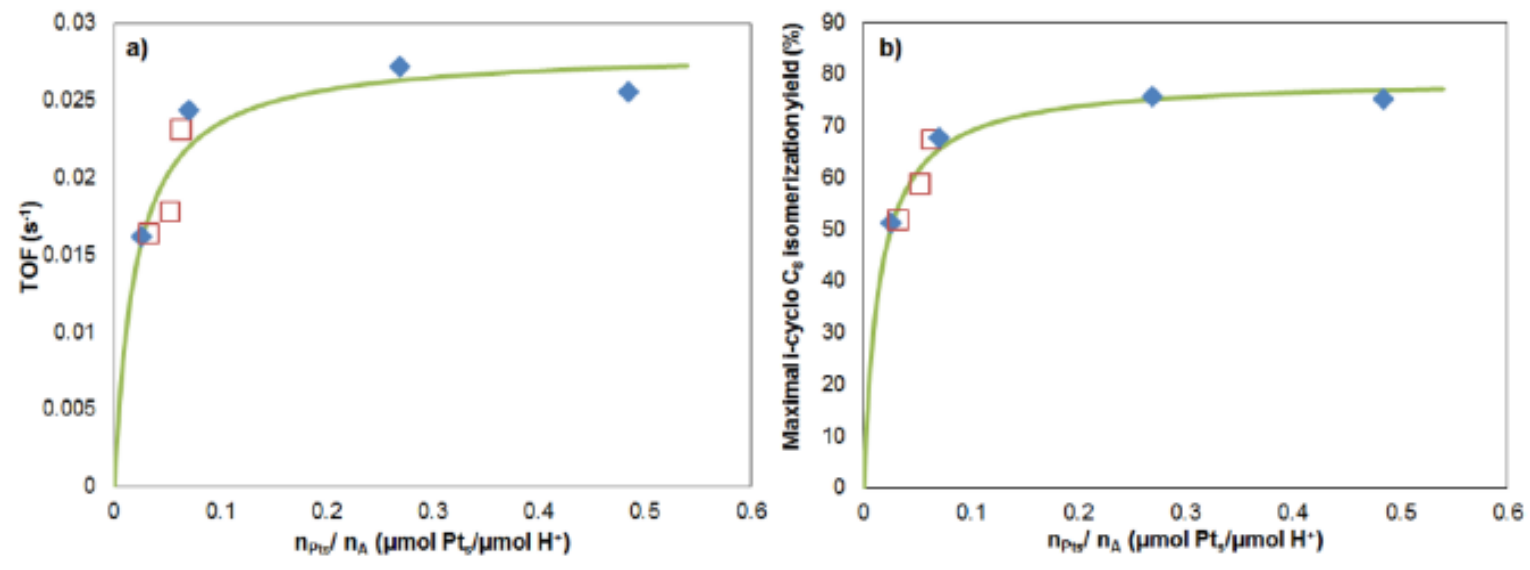

- microscale distance $\quad \square$ nanoscale distance $\_$Kinetic model

Figure 12. Evolution of the (a) TOF $\left(\mathrm{s}^{-1}\right)$ and (b) maximum i-cyclo $\mathrm{C}_{8}$ isomerization yield (\%) versus the metal/acid balance for both series of catalysts ${ }^{56}$. Reprinted with permission from 56 . Copyright 2018 American Chemical Society. 
Zečević et al. ${ }^{57}$ performed a more systematic study to control the proximity between the active sites of bifunctional $\mathrm{Pt} / \mathrm{Y}$ binder shaped catalysts, which are the most employed at the industrial level. ${ }^{32}$ Firstly, 50 wt.\% mesoporous zeolite Y (Y) and 50 wt.\% Al-binder (A) were mixed via extrusion to produce the acid support Y/A. The Pt metal anions from the $\mathrm{H}_{2} \mathrm{PtCl}_{6}$ solution at $\mathrm{pH}$ 3 were deposited on the Al-binder by an electrostatic adsorption method (Pt-A/Y). On the other hand, Pt metal cations from a $\mathrm{Pt}\left(\mathrm{NH}_{3}\right)_{4}\left(\mathrm{NO}_{3}\right)_{2}$ solution at $\mathrm{pH} 5$ were located in the zeolite by an ion-exchange method (Pt-Y/A). The almost equivalent Pt loadings of both bifunctional catalysts, 0.6 wt. $\%$ for Pt-Y/A and 0.7 wt.\% for Pt-A/Y, meet the required metal/acid balance for ideal hydrocracking. Moreover, it was verified that Pt particles were successfully placed inside the zeolite crystals and the alumina phase with the help of High-Angle Annular Dark-Field Scanning Transmission Electron Microscopy (HAADF-STEM) imaging and Energy Dispersive X-ray (EDX) elemental mapping of 70-nm-thick ultramicrotomed sections of the Pt-Y/A catalyst. Also, it was confirmed with the electron tomography that there was no Pt on the zeolite phase for PtA/Y and the alumina phase for Pt-Y/A catalysts. After the deposition process, two bifunctional catalysts were obtained with different arrangements of Pt particles. The HAADS-STEM images of a $70 \mathrm{~nm}$ thick section of both catalysts with Pt particles of $\sim 2.5 \mathrm{~nm}$ for Pt-Y/A, $\sim 3.5 \mathrm{~nm}$ for $\mathrm{Pt}-\mathrm{A} / \mathrm{Y}$ and an EDX map indicating Pt (yellow), Si (green) and $\mathrm{Al}$ (red) signals are shown in Figure 13. In Figure 13a and Figure 13b, Pt is located inside the zeolite pores with the closest proximity to the acid site. In Figure 13c and Figure 13d, Pt is deposited on the binder within a nanometer scale distance from the acid site. Additionally, since it is necessary to only assess the effect of the distance between metal and site on catalyst performance, all other morphologic parameters were required to be identically set. Because of this reason, the acidity of both 
catalysts was measured by temperature programmed desorption (TPD) of ammonia and results showed a similar level of acidity.
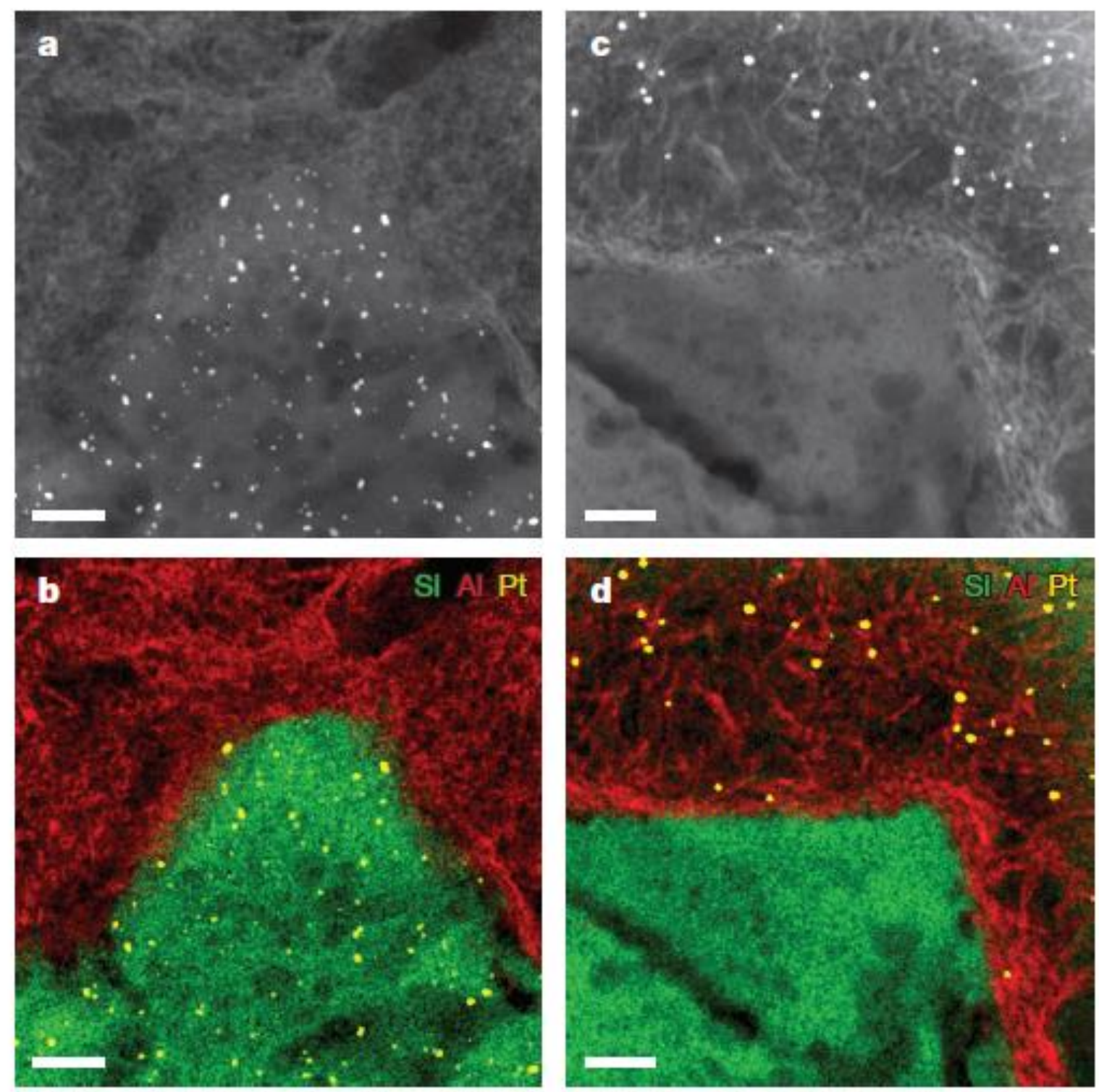

Figure 13. (a) HAADF-STEM image of Pt-Y/A with Pt particles residing within the zeolite crystals, (b) EDX map of Pt-Y/A, (c) HAADF-STEM image of Pt-A/Y with Pt particles residing on the alumina binder and (d) EDX map of Pt-A/Y ${ }^{57}$. Reprinted with permission from 57. Copyright 2015 Springer Nature. 
Experiments were performed at a pressure of $0.45 \mathrm{MPa}$ and an $\mathrm{H}_{2} / \mathrm{n}-\mathrm{C}_{10}$ molar ratio of 214 or pressure of $0.65 \mathrm{MPa}$ and an $\mathrm{H}_{2} / \mathrm{n}$-nonadecane $\left(\mathrm{n}-\mathrm{C}_{19}\right)$ or an $\mathrm{H}_{2} /$ pristane $\left(\mathrm{i}-\mathrm{C}_{19}\right)$ molar ratio of 14.6. According to the isomerization results shown in Figure 14a, Figure 14b, and Figure 14c, the conversion of $\mathrm{n}-\mathrm{C}_{10}$ and $\mathrm{n}-\mathrm{C}_{19}$ feedstocks over both catalysts are almost identical. However, the conversion of multi-branched $\mathrm{i}-\mathrm{C}_{19}$ over the Pt-Y/A catalyst is higher than the Pt-A/Y catalyst. Due to the steric nature of multi-branched i- $\mathrm{C}_{19}$ molecules, they possess a lower diffusivity in zeolites than their linear counterparts, with approximately $1.0 \cdot 10^{-11} \mathrm{~m}^{2} / \mathrm{s}$ for pristane compared to $1.0 \cdot 10^{-9} \mathrm{~m}^{2} / \mathrm{s}$ for $\mathrm{n}$-nonadecane ${ }^{57}$. Therefore, their conversion becomes more limited by diffusion and a closer distance between metal and acid sites is beneficial.
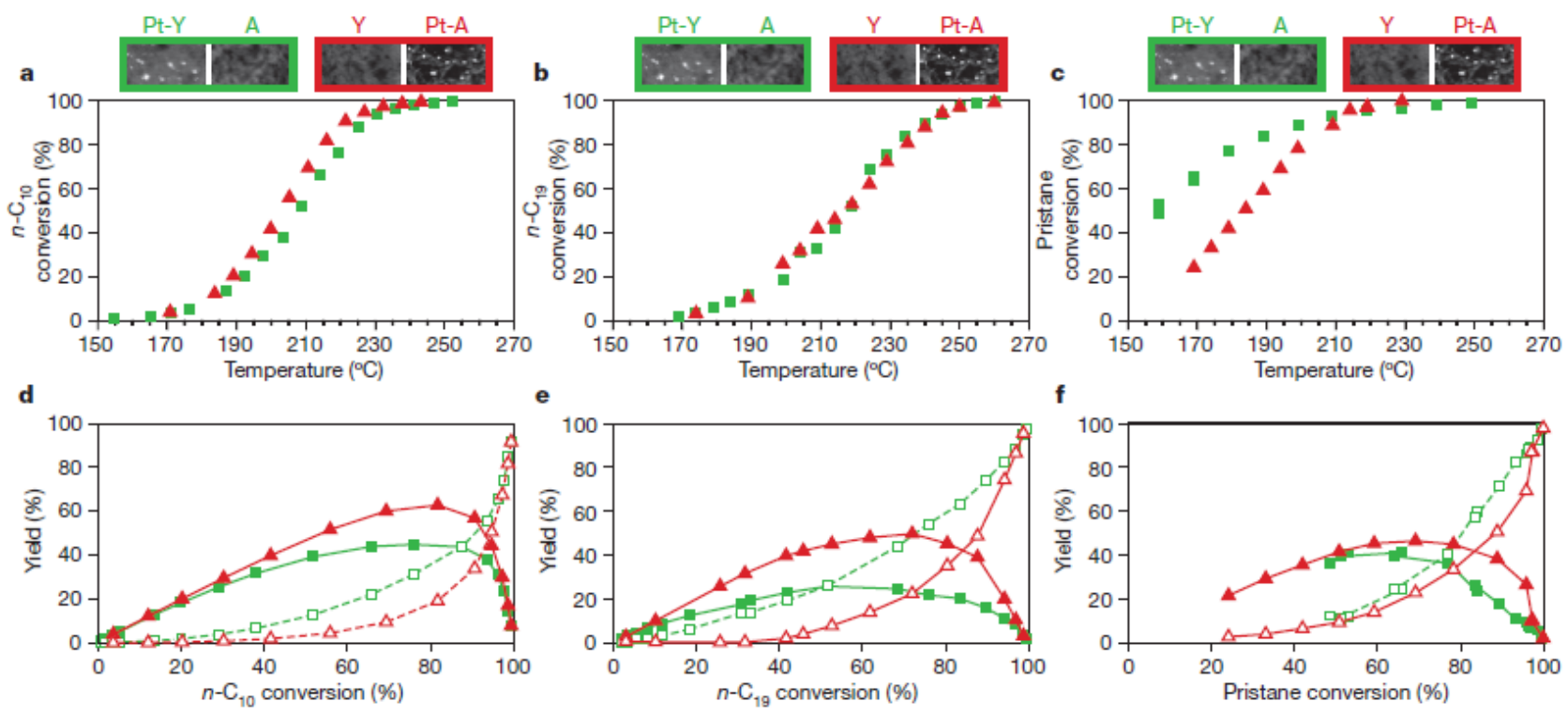

Figure 14. Conversion of (a) $n-C_{10}$, (b) $n-C_{19}$, and (c) $i-C_{19}$ as a function of the reaction temperature over Pt-Y/A (green squares) or Pt-A/Y (red triangles). Product yields from (d) n- $\mathrm{C}_{10}$, (e) n- $\mathrm{C}_{19}$, and (f) i- $\mathrm{C}_{19}$ feedstocks. (Solid lines and filled symbols: isomerized products; dashed lines and open symbols: cracked products) ${ }^{57}$. Reprinted with permission from 57. Copyright 2015 Springer Nature. 
Furthermore, both catalysts show different selectivities for all three feedstocks, as shown in Figure 14d, Figure 14e, and Figure 14f. The Pt-A/Y catalyst, with the metal function located on the alumina binder, shows a higher yield of isomer products than the Pt-Y/A catalyst, with the Pt sites located on the zeolite. The trend exhibited by the yield of cracked products further complements this observation, with the increased production of cracked products for Pt-Y/A. These results suggest the necessity of a closer proximity between sites for favoring cracking reactions. For the Pt-Y/A catalyst, where Pt metal particles are located inside the zeolite crystal and in the closest proximity with acid sites, the alkane feedstock diffuses through the micropores of the zeolite to undergo a HD/DHD reaction at the metal site. It is suggested that the intermediate molecules generated on the metal sites are retained in the zeolite micropores network due to their strong adsorption on acid sites and hindered diffusivity along the zeolite's micropores. Consequently, intermediate molecules experience a longer residence time in the acidic environment, which in turn leads to an increased cracking possibility and a decreased selectivity towards the desired products. On the other hand, for the Pt-A/Y catalyst, acid sites seem to be more accessible for the alkene intermediates formed on the metal sites. The alkene intermediates generated on the metal site diffuse from the wider pores of the alumina binder to the Y-zeolite, where they undergo isomerization on the outer region of the pore mouths and then diffuse back to a metal site on the alumina binder. Consequently, the cracking of alkene intermediates is reduced, and the isomer product yield is increased. The relevance of these findings lies within the apparent contradiction with the traditionally established notion that the metal and acid functions are required to be as close as possible for achieving an ideal hydrocracking behavior. Additional experimental considerations, such as the use of hydrocarbon chains with different shapes and sizes, and a more sophisticated catalyst design strategy with 
nanoscale intimacy control, provided a more clear vision on intimacy. This vision presents an expanded scope for the intimacy criterion that goes beyond just the distance between metal and acid sites. Specifically, it considers the interplay between the spatial arrangement of bifunctional sites and the transport of intermediates within the catalyst as a better foundation for defining an intimacy criterion. Careful considerations of the material properties of that dictate the mass transport of intermediates, such as pore size and topology, can be employed as a guideline for defining catalyst design. Zečević et al also presented the controlled placement of active sites as a strategy for tailoring bifunctional catalyst performance. ${ }^{57}$

One of the most extensively used methods for the preparation of bifunctional catalysts for hydrocracking is the incipient wetness impregnation (IWI) method, which provides various diameters and locations of Pt metal particles. ${ }^{58}$ If there is a non-uniform distribution of $\mathrm{Pt}$ particles, it can be difficult to isolate the impact of the distance between the metal and acid sites on catalyst performance. ${ }^{59}$ In contrast, the colloidal impregnation (CI) method represents a more novel approach with elevated nanometer scale distribution control technologies. ${ }^{60}$ A colloidal solution including $\mathrm{Pt}$ particles with homogenous diameter is prepared, then the solution is impregnated into supports. ${ }^{61}$ If the diameters of the Pt particles are larger than the size of the pore mouth of the support, the Pt particles are located on the external surface. ${ }^{59}$

In the study conducted by Lv et al., ${ }^{59}$ a series of Pt/SAPO-11 catalysts were prepared by using IWI, CI, and a combination of CI and IWI (CI-IWI) methods with different wt.\% Pt loadings. The weight percentages (x) of Pt in the catalysts prepared by the IWI, CI, and CI-IWI methods are labeled as IWIx, CIx, and CIx-IWIx respectively. For the CIx-IWIx catalyst, an additional amount of Pt (x wt.\%) was deposited on the CIx catalyst by applying the IWI method. The structural, acidity, and textural properties of the support and catalyst were tested by X-Ray 
Diffraction (XRD) patterns and $\mathrm{NH}_{3}$-TPD profiles, with no noticeable alterations detected. The distribution of $\mathrm{Pt}$ sites on the Pt/SAPO-11 catalyst was determined through $\mathrm{H} 2$ chemisorption, and its results are shown in Table 1. The characterization results indicate that Pt sites on CIprepared catalysts were primarily located on the larger external surface through electrostatic interactions since the colloidal Pt particles $(2.9 \mathrm{~nm}$ ) have a uniform and larger diameter than the smaller micropores of SAPO-11 (0.63 nm). In comparison, the Pt sites on IWI-prepared catalysts were mostly distributed in a non-uniform manner. Smaller particles $(1.0 \mathrm{~nm})$ are mainly located near the micropore mouth of SAPO-11 and the larger particles $(8.0 \mathrm{~nm})$ are deposited on the external surface as displayed in Table 1. ${ }^{59}$

Table 1. Pt site distribution on Pt/SAPO-11 catalysts ${ }^{59}$. Reprinted with permission from 59. Copyright 2018 Elsevier.

\begin{tabular}{c|c|c|c} 
& $\boldsymbol{C}_{\boldsymbol{P t}}^{\text {total }}(\mathrm{mmol} / \mathrm{g})$ & $\boldsymbol{C}_{\boldsymbol{P t}}^{\text {surf }}(\mathrm{mmol} / \mathrm{g})$ & $\boldsymbol{C}_{\boldsymbol{P t}}^{\text {mouth }}(\mathrm{mmol} / \mathrm{g})$ \\
CI0.25 & 2.6 & 2.6 & - \\
CI0.75 & 8.3 & 8.3 & - \\
IWI0.25 & 6.9 & 0.8 & 6.1 \\
CI0.5-IWI0.25 & 9.0 & 5.1 & 3.9
\end{tabular}

Their catalytic performance, including conversion and selectivity, was assessed using $n-\mathrm{C}_{19}$ as a model feedstock in a stainless steel fixed-bed reactor at temperatures between $290-370^{\circ} \mathrm{C}$, a pressure of $8.0 \mathrm{MPa}$, a $15-25 \mathrm{H}_{2} / \mathrm{n}-\mathrm{C}_{19}$ molar ratio and a liquid hourly space velocity (LHSV) of 2-4 $1 / \mathrm{h}$. The conversion of $\mathrm{n}^{-\mathrm{C}_{19}}$ over the Pt/SAPO-11 catalysts as a function of the temperature is shown in Figure 15a. Firstly, the conversion of $n-C_{19}$ for all catalysts increases with the temperature. The conversion and isomerization selectivity of the prepared Pt/SAPO-11 increased in the following order: CI0.1 $<$ CI0.25 $<$ CI0.5 $\approx$ CI0.75 $\approx$ CI1 $.0<$ CI0.5- IWI0.25 $<$ IWI0.25. The catalysts prepared by the CI method appear to be less active than the IWI0.25 and the CI0.5- 
IWI0.25 catalysts since they require higher reaction temperatures to reach the same conversion level. Moreover, as shown in Figure 15b, the IWI0.25 and CI0.5-IWI0.25 catalysts exhibit higher isomerization selectivity than the catalysts prepared by the CI method. It was proposed that the isomerization selectivity can be enhanced by raising the concentration of the Pt sites close to the micropore mouth. ${ }^{59}$
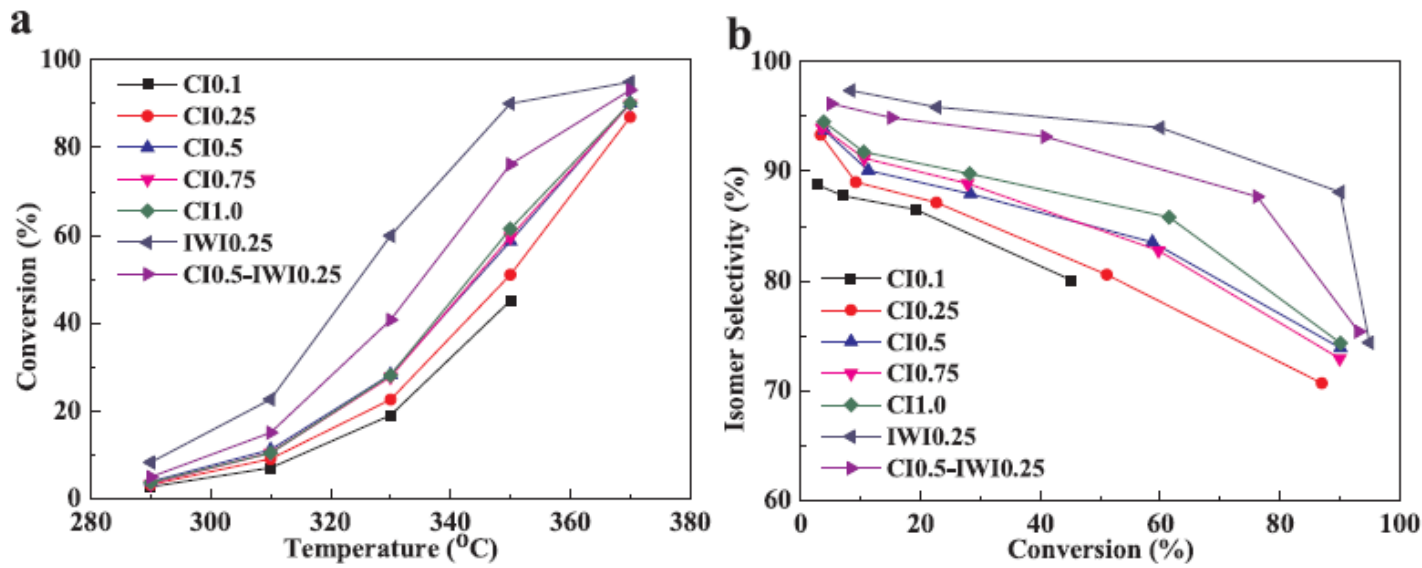

Figure 15. (a) Conversion of $n-C_{19}$ as a function of reaction temperature and (b) isomerization selectivity as a function of conversion of $\mathrm{n}-\mathrm{C}_{19}$ for Pt/SAPO-11 catalyst ${ }^{59}$ Reprinted with permission from 59. Copyright 2018 Elsevier.

Since all of the prepared catalysts have the same acidity, differences in the $\mathrm{n}_{\mathrm{Me}} / \mathrm{n}_{\mathrm{A}}$ ratio correspond to different loadings of $\mathrm{Pt}$ sites. The TOF as a function of the $\mathrm{n}_{\mathrm{Me}} / \mathrm{n}_{\mathrm{A}}$ ratio is presented in Figure 16, indicating the changes in activity. For the CI catalysts, the TOF increases considerably until a $\mathrm{n}_{\mathrm{Me}} / \mathrm{n}_{\mathrm{A}}$ value of around 0.0115 . After this value their activity remains largely the same for the rest of CI catalysts with higher Pt loadings. This means that a sufficient number of Pt particles has been reached and that the rate-limiting step changed from the metal to the acid function. Moreover, it can be seen that the CI0.5-IWI0.25 and IWI0.25 catalyst exhibit a higher TOF than the CI0.75 catalyst, even though both of them have a similar $\mathrm{n}_{\mathrm{Me}} / \mathrm{n}_{\mathrm{A}}$ ratio. These results suggest that a higher concentration of $\mathrm{Pt}$ sites on the external surface has an insignificant 
effect on catalyst activity for high $\mathrm{n}_{\mathrm{Me}} / \mathrm{n}_{\mathrm{A}}$ values. On the other hand, the effect of increasing the amount of $\mathrm{Pt}$ sites close to the micropore mouth is quite significant. Therefore, it would be more advantageous to increase the amount of Pt particles close to the micropore mouths in order to improve the activity of the Pt/SAPO-11, rather than just simply increasing the $\mathrm{n}_{\mathrm{Me}} / \mathrm{n}_{\mathrm{A}}$ ratio.

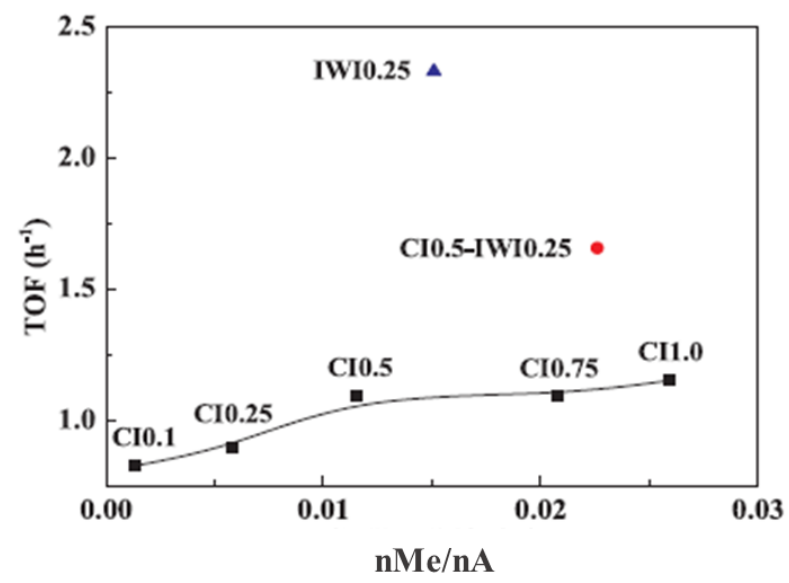

Figure 16. TOF versus $n_{M e} / n_{A}$ values ${ }^{59}$. Reprinted with permission from 59. Copyright 2018 Elsevier.

Additionally, product distributions for IWI0.25, CI0.75, and CI0.5-IWI0.25 were investigated to analyze the effect of the distribution of the Pt sites on the product selectivity. The product distributions for the IWI0.25, CI0.75, and CI0.5-IWI0.25 catalysts are presented in Figure 17. It can be seen that the isomerization selectivity towards mono-branched isomers is also enhanced by raising the concentration of the Pt sites close to the micropore mouths. 
a

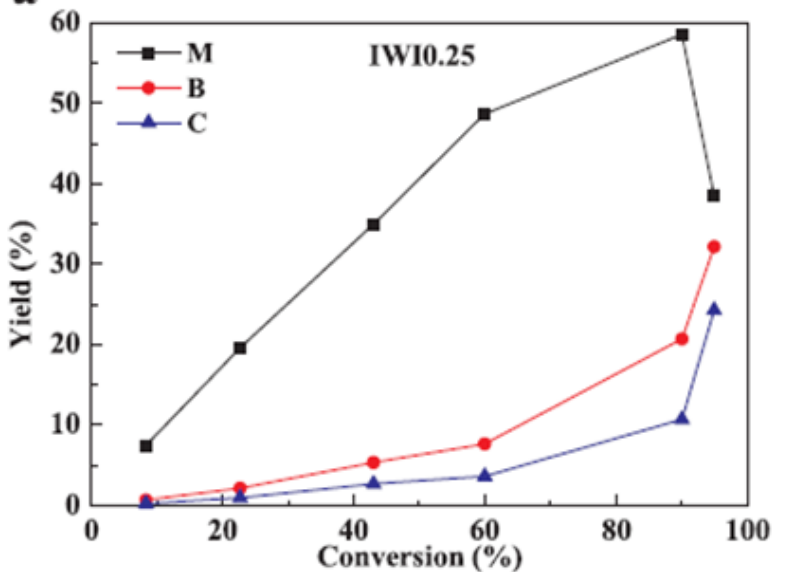

c

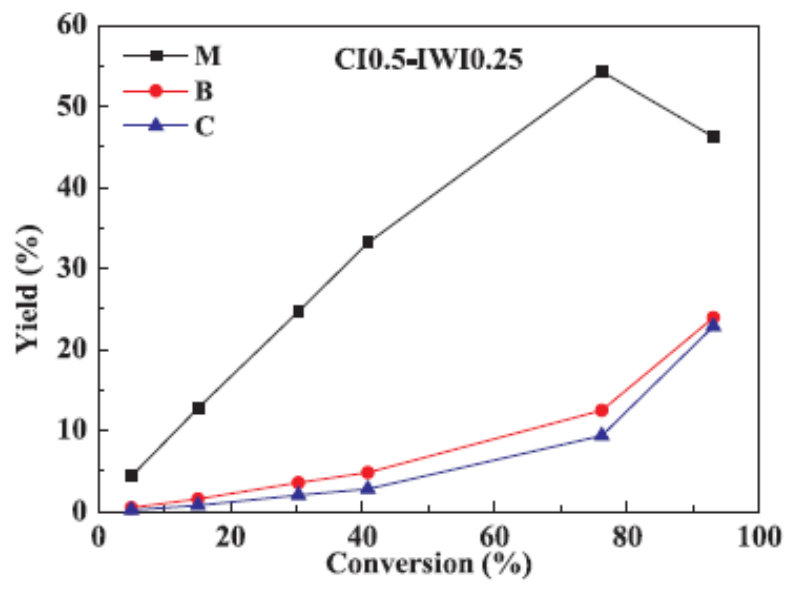

b

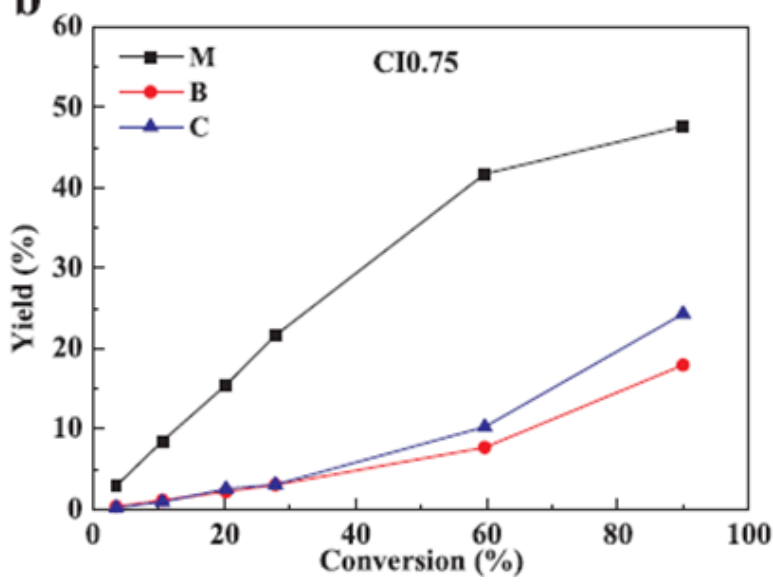

Figure 17. Product distributions over Pt/SAPO-11 catalysts. (a) IWI0.25, (b) CI0.75, (c) CI0.5IWI0.25 (M: mono-branched, B: multi-branched isomers, C: cracking products) ${ }^{59}$. Reprinted with permission from 59. Copyright 2018 Elsevier.

An explanation for this behavior can be based on the reaction mechanism. Alkene intermediates formed on the metal site diffuse to the acid site during the n-alkane hydroisomerization process. There, they undergo skeletal rearrangement to yield the corresponding i-alkenes. If the distance between metal and acid sites is too large, the possibility of encountering an acid site decreases due to the long diffusional path. Thus, the transformation of n-alkenes becomes hindered, decreasing the conversion of n-alkanes in the process. On the 
other hand, positioning more metal sites close to the micropore mouths provides shorter metal and acid distances than those given by the placement of metal sites on the external surface. Such closer proximities cause acid sites to be more accessible for n-alkene intermediates, which consequently derives in an enhanced n-alkane conversion and a higher isomerization selectivity. Once isomerization takes place on the acid sites, the i-alkene intermediates can either diffuse back to the metal sites to be hydrogenated into i-alkanes, or encounter more acid sites where additional rearrangement or cracking reactions occur. ${ }^{62}$ Naturally, i-alkene intermediates can diffuse more easily towards Pt sites if these are located close to the micropore mouth, resulting in higher isomer yields. Contrarily, if the Pt sites are located far from the acid sites, additional skeletal rearrangements and cracking reactions become more likely, causing the yields of multibranched isomers and cracking products to increase. In conclusion, the placement of the Pt sites, and their separation with acid sites, can have a significant impact on product selectivity. It would be preferable to deposit the Pt sites close to the mouths of the zeolite's micropores. ${ }^{59}$

Effects of the zeolite particle size and thickness on bifunctional catalyst performance Apart from the metal loading methods, zeolite crystal particle size and thickness also affect the distance between metal and acid functions within the microporous or mesoporous structure on the catalyst. Multiple studies have specifically investigated the effect of the zeolite particle size on the distance and the performance of the bifunctional catalysts.

Li et al. ${ }^{63}$ investigated the hydroisomerization of $\mathrm{n}-\mathrm{C}_{10}$ over two different bifunctional catalysts supports of $\gamma$-alumina binder and zeolite. The first one without additional changes (Pt/AY-ori) while the second was alkali-treated (Pt/AY-alk). Alkali-treatments to the original Y zeolite prior to Pt deposition led to different crystal particle sizes of the zeolite components. The alkali-treatments to the Y zeolite prior to Pt deposition led to different crystal particle sizes of the 
zeolite components. The average zeolite crystals size for Y-ori and Y-alk were found by XRD analysis to be $687 \mathrm{~nm}$ and $501 \mathrm{~nm}$, respectively. The Pt particles were placed on the Y-alumina material by the electrostatic adsorption method. The hydroisomerization reaction of $n-C_{10}$ was conducted in a stainless-steel batch-type reactor at a temperature of $280^{\circ} \mathrm{C}$ and pressure of 2.0 MPa.

The SEM images of Pt/AY-ori and Pt/AY-alk catalysts are illustrated in Figure 18. The Y-ori particles have a cleaner and smoother outer surface, whereas the Y-alk particles have irregular shapes, rough boundaries, and large openings on the zeolite outer layers. The imperfect areas located on the outer surface of zeolite crystals are mainly caused by the dissolution of the zeolite crystal framework in alkali conditions. ${ }^{64}$ Moreover, the textural properties, including $\mathrm{S}_{\mathrm{BET}}, \mathrm{V}_{\text {tot }}$ and $\mathrm{V}_{\text {mic }}$, and metal and acid characteristics of catalysts are quite similar.
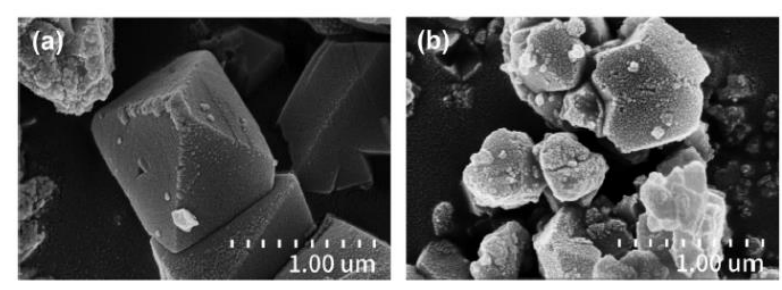

Figure 18. SEM images of zeolite samples: (a) Y-ori and (b) Y-alk ${ }^{63}$. Reprinted with permission from 63. Copyright 2019 Elsevier.

In Figure 19, the graph of the $\mathrm{n}-\mathrm{C}_{10}$ conversion versus reaction time for both Pt/AY-ori and $\mathrm{Pt} / \mathrm{AY}$-alk catalysts is shown, indicating that the Pt/AY-alk catalyst exhibits a slightly higher activity than the Pt/AY-ori catalyst. This is mainly caused by the improved dispersion of the Brønsted acid sites on the Pt/AY-alk catalyst as compared to Pt/AY-ori. This improved dispersion is achieved by the reduced size of the zeolite crystals obtained with the alkali treatment. ${ }^{65}$ With a better acid site dispersion, alkene intermediates are less likely to only diffuse through the non-acidic alumina route between two metal sites in Pt/AY-alk. 


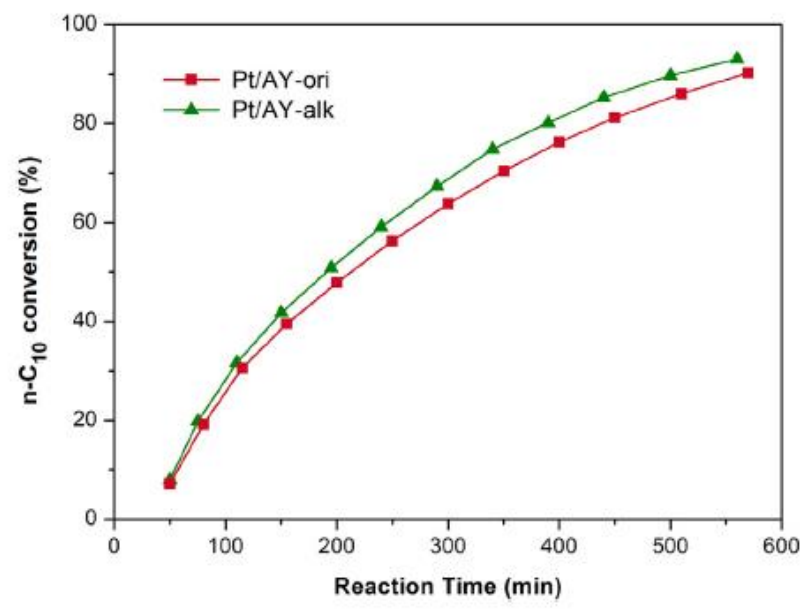

Figure 19. Time evolution of $n-C_{10}$ conversion over Pt/AY-ori (green) and Pt/AY-alk (red) ${ }^{63}$. Reprinted with permission from 63. Copyright 2019 Elsevier.

The isomerization and cracking products distribution as a function of the $\mathrm{n}-\mathrm{C}_{10}$ conversion over Pt/AY-ori and Pt/AY-alk catalysts are shown in Figure 20a. The solid lines with filled symbols show the $\mathrm{i}-\mathrm{C}_{10}$ yield and the solid lines with open symbols show the yield of cracked products (mostly $\mathrm{n}-\mathrm{C}_{4}, \mathrm{n}-\mathrm{C}_{5}$ and $\mathrm{n}-\mathrm{C}_{6}$ ). The $\mathrm{Pt} / \mathrm{AY}$-alk catalyst provides more isomerized products than the Pt/AY-ori catalyst and has better resistance to unwanted secondary cracking reactions. Furthermore, in Figure 20b, the ratios of multi-branched to mono-branched isomers $(\mathrm{MuB} / \mathrm{MB})$ are plotted against the $\mathrm{n}-\mathrm{C}_{10}$ conversion, where the $\mathrm{Pt} / \mathrm{AY}$-alk catalyst exhibits lower $\mathrm{MuB} / \mathrm{MB}$ ratios than those of the Pt/AY-ori catalyst. It is claimed that the shorter diffusion distance of an intermediate molecule within the micropores can be achieved with a smaller zeolite crystal size. As mentioned before, ideal hydroconversion is characterized by the consecutive conversion of $n-C_{10}$ molecules into mono-branched $\mathrm{i}-\mathrm{C}_{10}$, multi-branched $\mathrm{i}-\mathrm{C}_{10}$ and finally into cracking products. Contrarily, for a non-ideal hydroconversion, mono-branched isomers, multi-branched isomers, and cracking products are produced simultaneously. A lower zeolite crystal size results in a lower number of acid sites that intermediate molecules can 
encounter during their movement inside the zeolite microporous structure and a decreased possibility of undesired secondary reactions. ${ }^{65}$ Furthermore, multi-branched alkanes are more sensitive to cracking reactions than mono-branched alkanes. ${ }^{40,37,62}$ As a result, the Pt/AY-alk catalyst outperforms the Pt/AY-ori catalyst, leading to higher selectivity toward to isomerization and limited cracking products. ${ }^{63}$
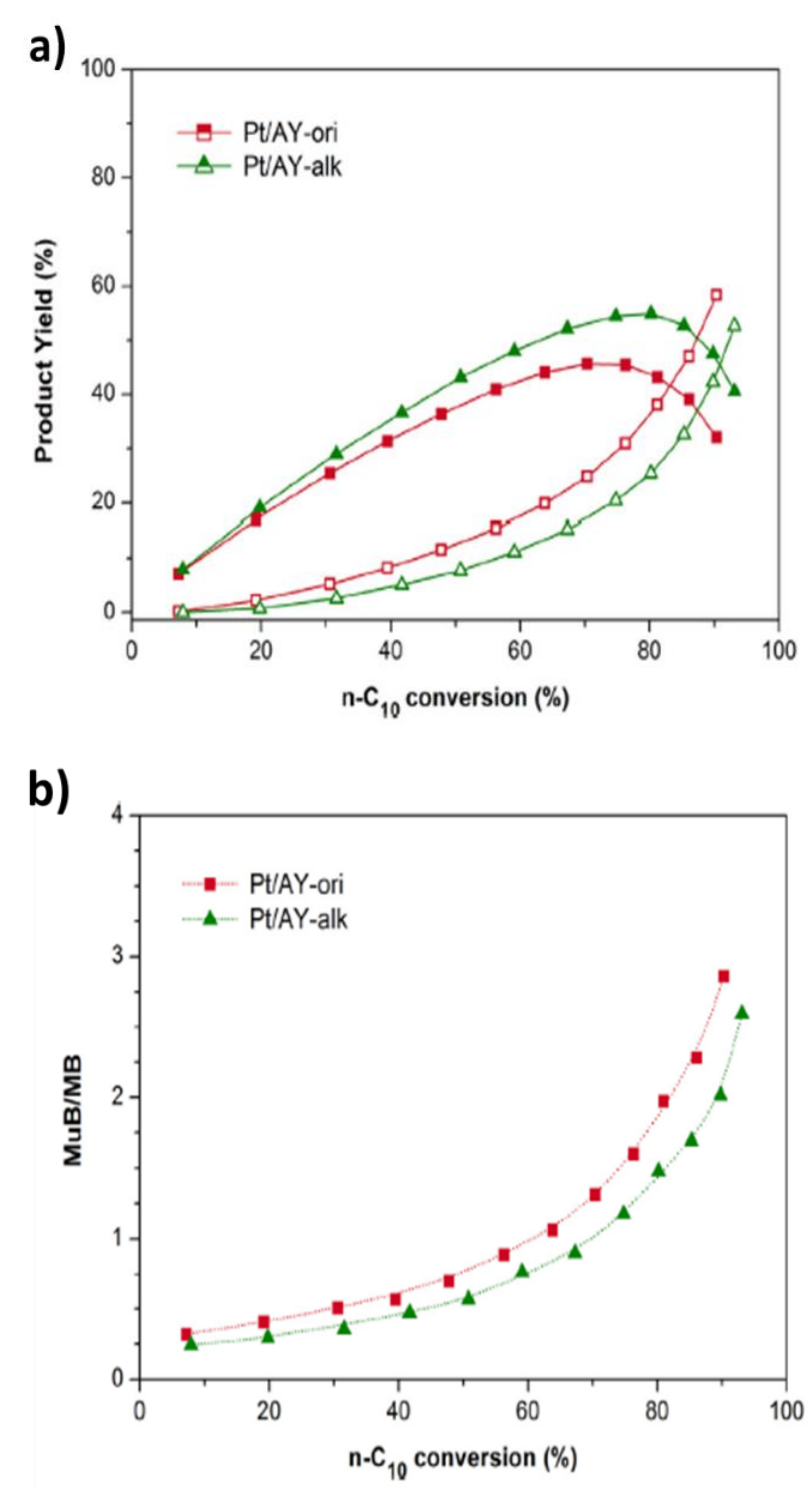

Figure 20. (a) Distribution of isomerized product (solid lines with filled symbols) and cracking products (solid line with open symbols) versus $n-C_{10}$ conversion (b) $M u B / M B$ value of 
isomerized product against $\mathrm{n}-\mathrm{C}_{10}$ conversion ${ }^{63}$. Reprinted with permission from 63. Copyright 2019 Elsevier.

Zhang et al. ${ }^{66}$ investigated the performance of micro/mesoporous Pt metal loaded Y/MCM-41 bi-porous composite bifunctional catalysts for the hydroisomerization of $n$-dodecane $\left(n-\mathrm{C}_{12}\right)$. The Y/MCM-41 materials include the previously mentioned Y-zeolite and alkali-treated Y-zeolites treated for 2 and 5 hours, respectively represented as MY-0, MY-2, and MY-5. The prepared catalysts (Pt/MY-0, Pt/MY-2, and Pt/MY-5) possess similar metal/acid balances (i.e. $\mathrm{n}_{M e} / \mathrm{n}_{\mathrm{A}}$ values) but different average Y zeolite crystal particle sizes. As shown in Figure 21, particle sizes of the $\mathrm{Y}$ zeolite crystals become smaller with the alkali-treatment and this reduction is related to the treatment time. The mean particle size for MY-0, MY-2, and MY-5 were found to be $653 \mathrm{~nm}, 548 \mathrm{~nm}$, and $421 \mathrm{~nm}$, respectively. Afterwards, the deposition procedure of the 0.7 wt.\% Pt loadings on the Y/MCM-41 materials was performed using the IWI method with a $\mathrm{H}_{2} \mathrm{PtCI}_{6}$ aqueous solution as a precursor. Since the average diameter of Pt crystal particles (4.0 $\mathrm{nm})$ were larger than the zeolite micropores $(1.0 \mathrm{~nm})$, the Pt metal particles were deposited on the mesoporous MCM-41 materials and external surfaces of the Y-zeolite crystals. n- $\mathrm{C}_{12}$ isomerization took place in a batch-type reactor at a temperature of $270^{\circ} \mathrm{C}$ and a pressure of 2.0 MPa. 

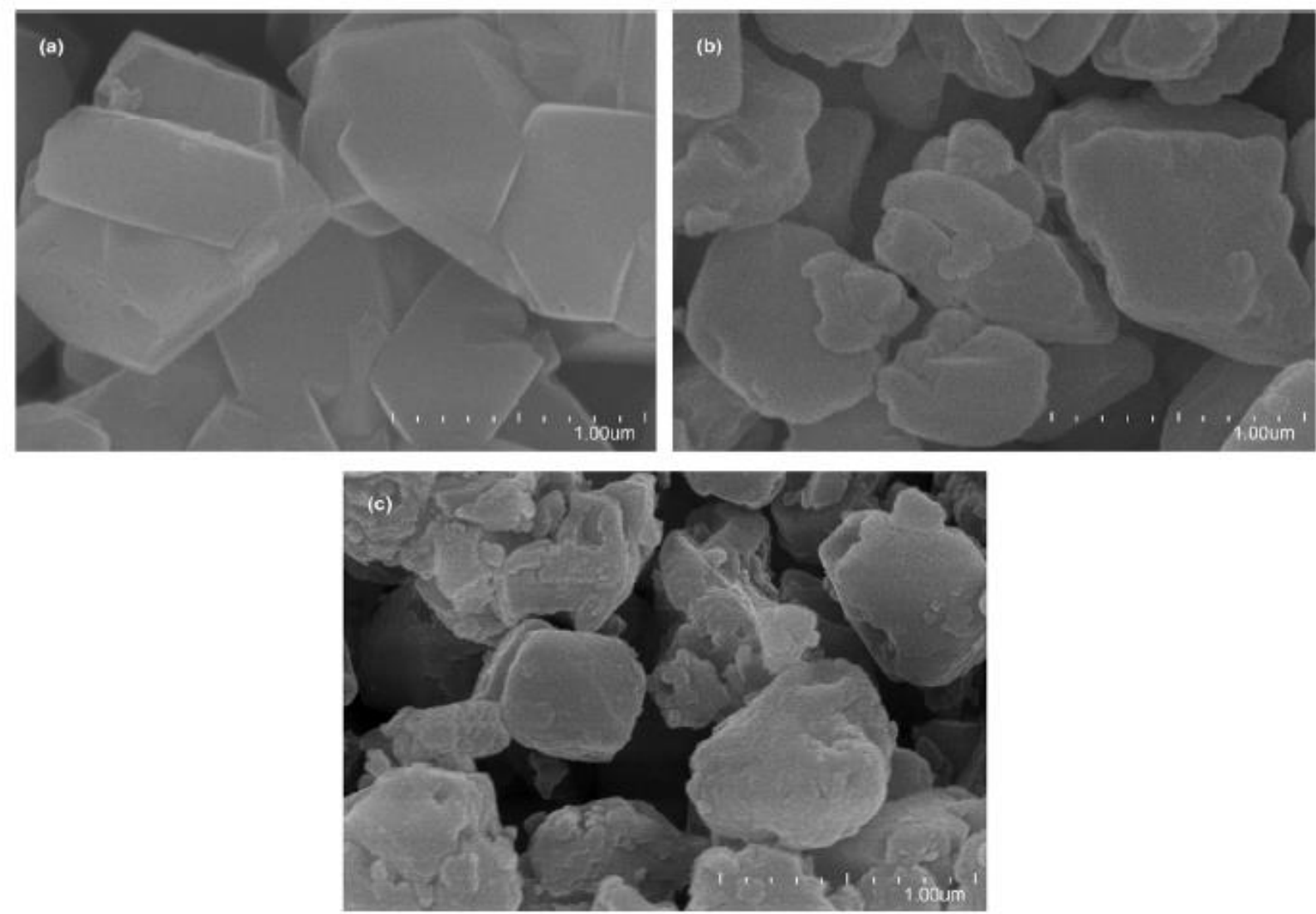

Figure 21. SEM images of Y zeolite crystals: (a) Y-0, (b) Y-2, and (c) Y-5 ${ }^{66}$. Reprinted with permission from 66. Copyright 2019 Elsevier.

The isomerization selectivity of the long-chain alkanes on the microporous arrays becomes suppressed due to the strong adsorption of alkene intermediates on the acid sites and slower diffusion of heavy molecules. ${ }^{57}$ On the other hand, transport limitations are less pronounced on the mesoporous MCM-41 materials due to their high specific surface area, large pore volume, and wide pore diameter. ${ }^{67}$ However, the weak acidity of the mesoporous MCM-41 material is one of the main drawbacks preventing a high efficiency in feedstock conversion. ${ }^{68}$ Therefore, the Pt metal-loaded micro/mesoporous composite catalyst is developed by combining the most favorable features of both microporous crystalline zeolites and mesoporous materials. ${ }^{69}$ The microporous zeolite provides a high acidity, whereas the mesoporous nature of the MCM-41 
material results in less pronounced diffusion limitations and shorter molecular residence times. ${ }^{70,71}$ The composite catalyst is formed as a result of coating the external surface of Y-zeolite crystals with the mesoporous MCM-41 layer. Additionally, there is another independent MCM41 mesoporous phase around the composite particles. Both of these, the layer covering the external surface and the independent layer, work harmoniously to impede a close proximity between the Y-zeolite crystals, providing them with a better dispersion in the bi-porous catalytic system. Given this condition, the possibility of extended lengths of molecular diffusion within microporous pathways resulting from the close contact of contiguous zeolite crystals is minimized. ${ }^{66}$ Figure 22 shows the TEM images of the prepared Y/MCM-41 samples (MY-0, MY-2, MY-5), which provide a visualization of both aforementioned types of mesoporous phases.
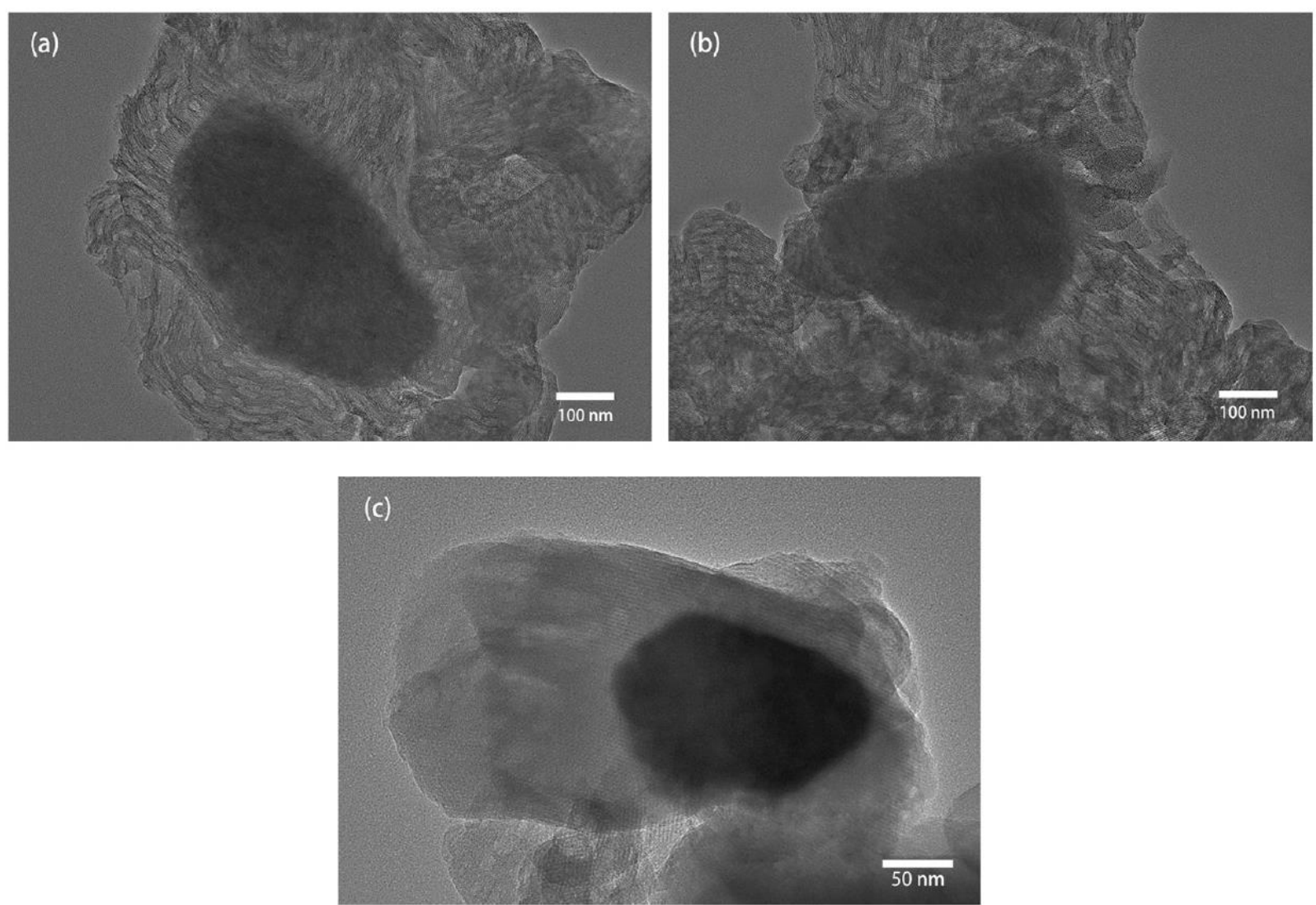
Figure 22. TEM images of (a) MY-0; (b) MY-2; (c) MY-5 ${ }^{66}$. Reprinted with permission from 66. Copyright 2019 Elsevier.

In Figure 23, the conversions of $\mathrm{n}-\mathrm{C}_{12}$ over the $\mathrm{Pt} / \mathrm{MY}-0, \mathrm{Pt} / \mathrm{MY}-2$, and $\mathrm{Pt} / \mathrm{MY}-5$ catalysts are plotted with respect to the reaction time. The Pt/MY-5 and Pt/MY-2 alkali-treated catalysts exhibit a superior conversion compared to the Pt/MY-0 catalyst. The results are related to the smaller particle sizes of the zeolite crystals and the better acid site dispersions for both Pt/MY-2 and $\mathrm{Pt} / \mathrm{MY}-5$.

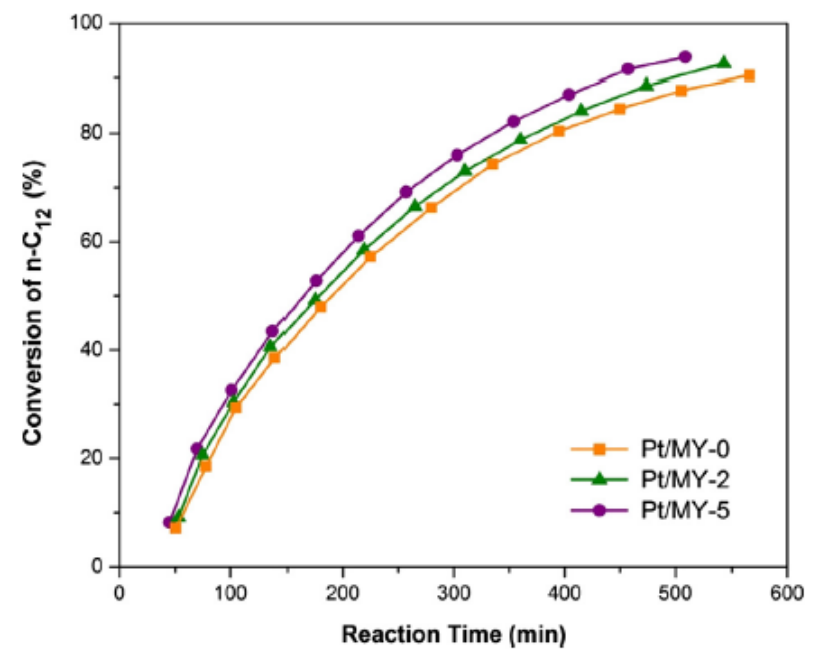

Figure 23. Batch time evolution of $n-C_{12}$ conversion for Pt/MY-0, Pt/MY-2, and Pt/MY-5 ${ }^{66}$. Reprinted with permission from 66. Copyright 2019 Elsevier.

Figure $24 \mathrm{a}$ shows the isomerized and cracked product yields for $\mathrm{n}-\mathrm{C}_{12}$ hydroisomerization of all three catalysts as functions of the $\mathrm{n}-\mathrm{C}_{12}$ conversion. Filled and hollow symbols represent the isomerized and cracked product yields, respectively. It can be seen that the alkali-treated catalysts, with a smaller particle size of the zeolite component, provide higher yields for the isomerized products and are less favorable towards cracked products than the Pt/MY-0 catalyst. This tendency becomes more clear at conversions higher than 20\%, with Pt/MY-5 achieving the 
peak isomerization yield at around $75 \%$ conversion. Furthermore, the product yield tendencies of Pt/MY-0 suggest a poor inhibition of undesired skeletal cracking reactions, particularly at high conversions. Figure $24 \mathrm{~b}$ displays the $\mathrm{MuB} / \mathrm{MB}$ values of $\mathrm{i}$-dodecane $\left(\mathrm{i}-\mathrm{C}_{12}\right)$ versus the corresponding conversion of $\mathrm{n}-\mathrm{C}_{12}$. The $\mathrm{MuB} / \mathrm{MB}$ values are higher for the Pt/MY-0 catalyst in comparison to both Pt/MY-2 and Pt/MY-5. This is an indication that the Pt/MY-0 catalyst generates multi-branched isomers more quickly and easily than the Pt/MY-2 and Pt/MY-5 catalysts. In turn, the poor cracking resistance of Pt/MY-0 could then be likely attributed to the increased cracking tendencies of multi-branched isomers. ${ }^{37}$ Similar conclusions to those provided in the aforementioned work of Li et al. ${ }^{63}$ can be drawn from these results. Given the larger particle size of Pt/MY-0, alkene intermediates diffusing through the zeolite crystals would have a longer residence time within the microporous structure before encountering the metal sites in the outer mesoporous shell. Therefore, intermediates interact with a greater number of acid sites and the likelihood of skeletal transformation reactions is increased, favoring the formation of multi-branched and cracked products. This is in contrast to the Pt/MY-2 and Pt/MY-5 catalysts, whose smaller particle size provides a shorter diffusion distance insides the zeolite crystals, and thus a lesser amount of interactions with the acid functions. Lastly, despite the almost identical metal and acid properties of the alkali-treated catalysts, $\mathrm{Pt} / \mathrm{MY}-5$ possesses a higher isomerization selectivity than Pt/MY-2 due to the former's smaller particle size. This leads to shorter diffusion distances to be traveled within the zeolite crystals and, in turn, an even lesser probability for shortened alkene intermediates to encounter more protonic acid sites between $\mathrm{HD} / \mathrm{HDH}$ reactions. As a result, unwanted reactions become more controlled and the bifunctional catalyst performance is increased. 

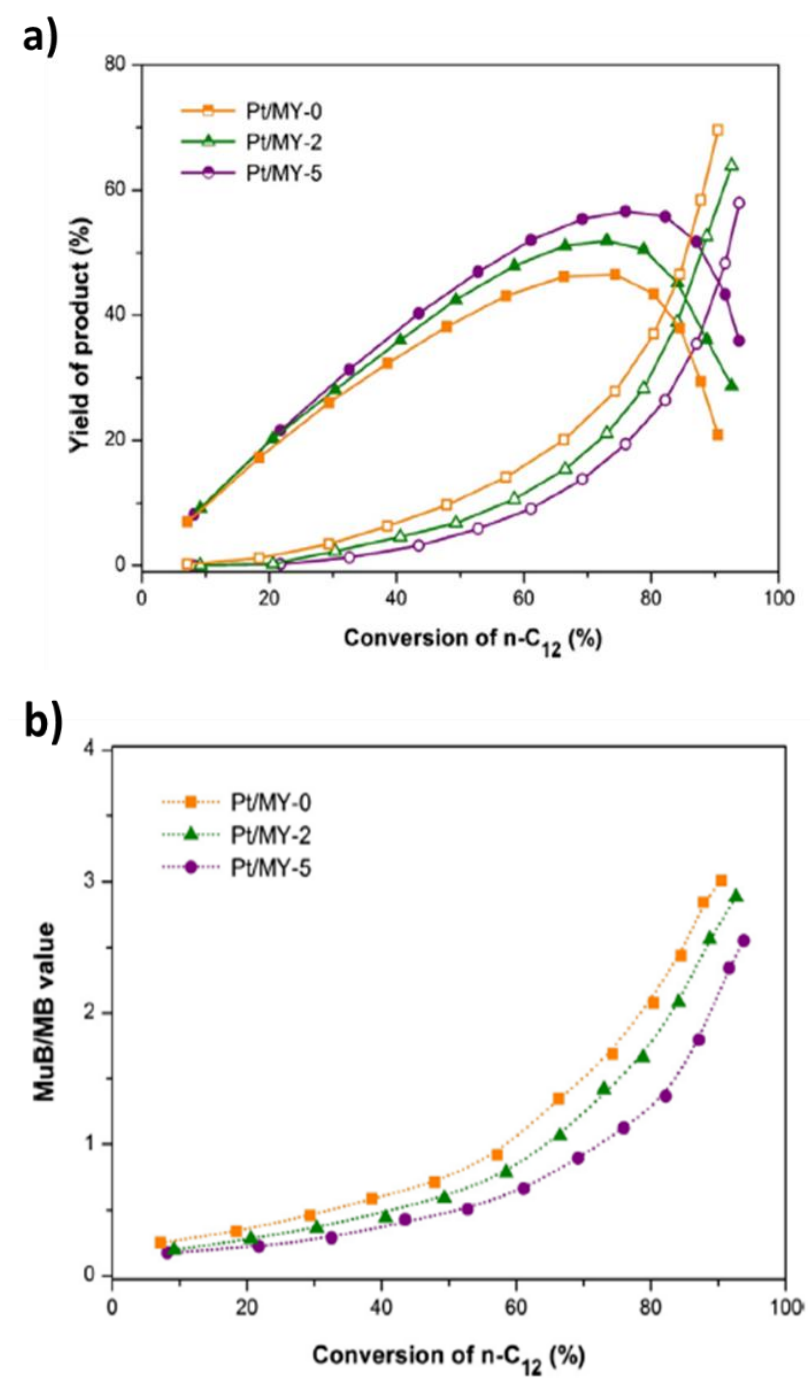

Figure 24. (a) Product yield versus conversion of $n-C_{12}$ (b) $M u B / M B$ values of isomerized products versus conversion of $n-C_{12}{ }^{66}$. Reprinted with permission from 66. Copyright 2019 Elsevier.

Kim et al. ${ }^{33}$ prepared a bifunctional catalyst with Pt nanoparticles (NPs) loaded on MFI-type (ZSM-5) zeolites and different crystal thicknesses ranging from 2 to $300 \mathrm{~nm}$ in order to explore the effect of zeolite crystal thickness and Pt location on the hydroisomerization of $n-C_{7}$. In this study, $2 \mathrm{~nm}$ thick MFI zeolite nanosheets, a $10 \mathrm{~nm}$ thick nanocrystalline MFI zeolite, a bulk zeolite with approx. $300 \mathrm{~nm}$ crystal thickness and a commercial MFI zeolite of $40 \mathrm{~nm}$ crystal 
thickness were produced and identified as NS-2, NC-10, B-300, and C-40, respectively. A reduction of the diffusion lengths by creating nanocrystalline zeolites or mesopores within the zeolite crystal provided a shorter duration of diffusion processes inside the zeolite micropores. The mesoporous zeolite and nanocrystalline zeolite catalysts show a significant improvement in the isomer selectivity of n-alkane hydroisomerization compared to the bulk zeolite. ${ }^{72}$ The Pt NPs were loaded inside the zeolite pores by ion-exchange (IE) technique and on the external surface of the crystal by the CI method. The Pt content of catalysts prepared by the IE and CI methods were within the range of 0.81-0.99 wt.\%, which was sufficient to supply the HD/DHD functions and keep Pt evenly dispersed in the catalytic system. The Pt locations and particle size of the conventional ZSM-5 and $2 \mathrm{~nm}$ thick MFI nanosheets prepared by IE and CI are displayed in Figure $25 .{ }^{33}$ For the catalysts prepared by the IE method, the Pt NPs are located near to acid sites, whereas for the catalysts prepared by the CI method, the Pt NPs are only deposited on the external surfaces. Moreover, it can be seen that for the $2 \mathrm{~nm}$ nanosheets the distance between metal and acid sites is almost the same, independently of the preparation method. Contrarily, for larger nanosheets, there is a large difference in the distance between metal and acid sites for both methods. The hydroisomerization of $\mathrm{n}-\mathrm{C}_{7}$ was performed in a continuous flow Pyrex reactor with an inner diameter of $13 \mathrm{~mm}$ under $\mathrm{H}_{2}$ at atmospheric pressure using $0.1 \mathrm{~g}$ of powdered catalyst. The $\mathrm{H}_{2} / \mathrm{n}-\mathrm{C}_{7}$ ratio, the reactor temperature and the WHSV of $\mathrm{n}-\mathrm{C}_{7}$ were set to $10,473-573 \mathrm{~K}$, and $6.8 \mathrm{~h}^{-1}$, respectively. 


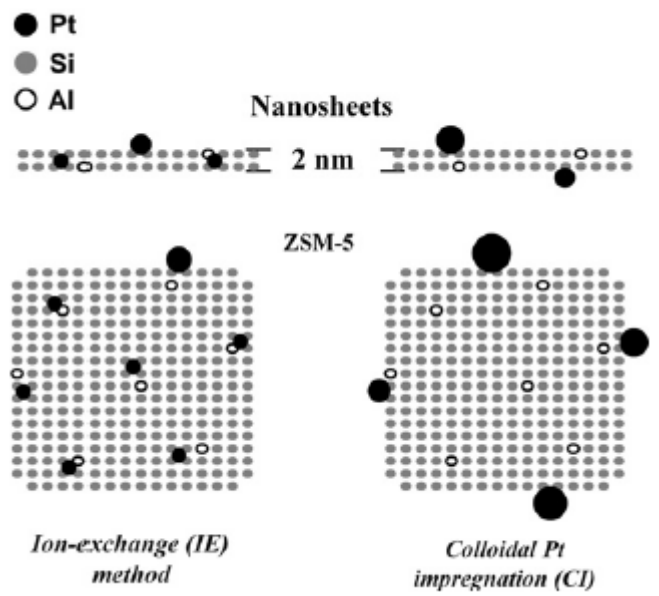

Figure 25. Schematic representation of Pt locations in conventional ZSM-5 and $2 \mathrm{~nm}$ thick MFI nanosheets prepared by the IE and CI methods ${ }^{33}$. Reprinted with permission from 33 . Copyright 2013 Elsevier.

Figure 26 illustrates the $n-C_{7}$ conversion over the $\operatorname{Pt}(\mathrm{IE}) / \mathrm{MFI}$ and $\mathrm{Pt}(\mathrm{CI}) / \mathrm{MFI}$ catalysts as a function of temperature. Since all results show a similar S-curves for different catalysts in both preparation methods, the catalysts had an enough number of HD/DHD Pt sites to balance the acidic function under the given reaction conditions. In the case of insufficient Pt sites, the conversion of alkanes is controlled by Pt loading and dispersion. 

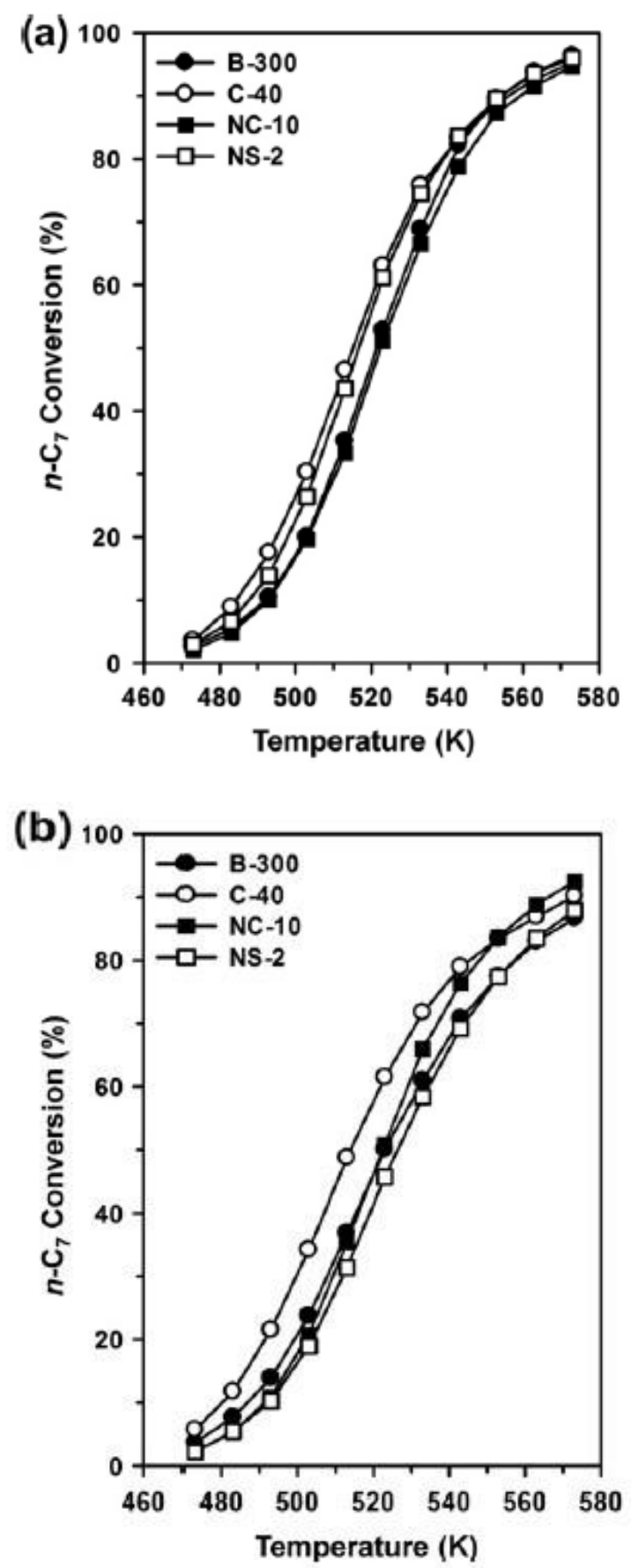

Figure 26. $n-C_{7}$ conversions over the (a) $\mathrm{Pt}(\mathrm{IE}) / \mathrm{MFI}$ and (b) $\mathrm{Pt}(\mathrm{CI}) / \mathrm{MFI}$ catalysts as a function of reaction temperature $(K)^{33}$. Reprinted with permission from 33. Copyright 2013 Elsevier.

In Figure 27, selectivity toward $\mathrm{i}-\mathrm{C}_{7}$ versus total $\mathrm{n}-\mathrm{C}_{7}$ conversion is plotted with increasing reaction temperatures and with arrows indicating the maximum obtained $\mathrm{i}-\mathrm{C}_{7}$ yield. For the same 
$n-C_{7}$ conversion level, the $i_{-} C_{7}$ yield increases with decreasing crystal thickness for both catalyst preparation methods. The maximum $\mathrm{i}_{-} \mathrm{C}_{7}$ yields for $\mathrm{Pt}(\mathrm{IE}) / \mathrm{B}-300, \mathrm{Pt}(\mathrm{IE}) / \mathrm{C}-40, \mathrm{Pt}(\mathrm{IE}) / \mathrm{NC}-10$, and $\mathrm{Pt}(\mathrm{IE}) / \mathrm{NS}-2$ were found as $22 \mathrm{~mol} \%, 29 \mathrm{~mol} \%, 42 \mathrm{~mol} \%$, and $48 \mathrm{~mol} \%$, respectively. On the other hand, the maximum $\mathrm{i}-\mathrm{C}_{7}$ mole percent for $\mathrm{Pt}(\mathrm{CI}) / \mathrm{B}-300, \mathrm{Pt}(\mathrm{CI}) / \mathrm{C}-40, \mathrm{Pt}(\mathrm{CI}) / \mathrm{NC}-10$ and $\mathrm{Pt}(\mathrm{CI}) / \mathrm{NS}-2$ were found as $14 \mathrm{~mol} \%, 27 \mathrm{~mol} \%, 42 \mathrm{~mol} \%$, and $49 \mathrm{~mol} \%$, respectively. When comparing both methods, all catalysts show a very similar maximum $\mathrm{i}-\mathrm{C}_{7}$ mole percent except for the $\mathrm{Pt}(\mathrm{IE}) / \mathrm{B}-300$ and $\mathrm{Pt}(\mathrm{CI}) / \mathrm{B}-300$ catalysts. However, the effect of the zeolite crystal thickness was more impactful than the location of the Pt NPs. For instance, the difference between the $\mathrm{Pt}(\mathrm{IE}) / \mathrm{NS}-2$ and $\mathrm{Pt}(\mathrm{IE}) / \mathrm{B}-300$ catalyst is much larger than the difference between the $\mathrm{Pt}(\mathrm{IE}) / \mathrm{B}-300$ and $\mathrm{Pt}(\mathrm{CI}) / \mathrm{B}-300$ catalysts.

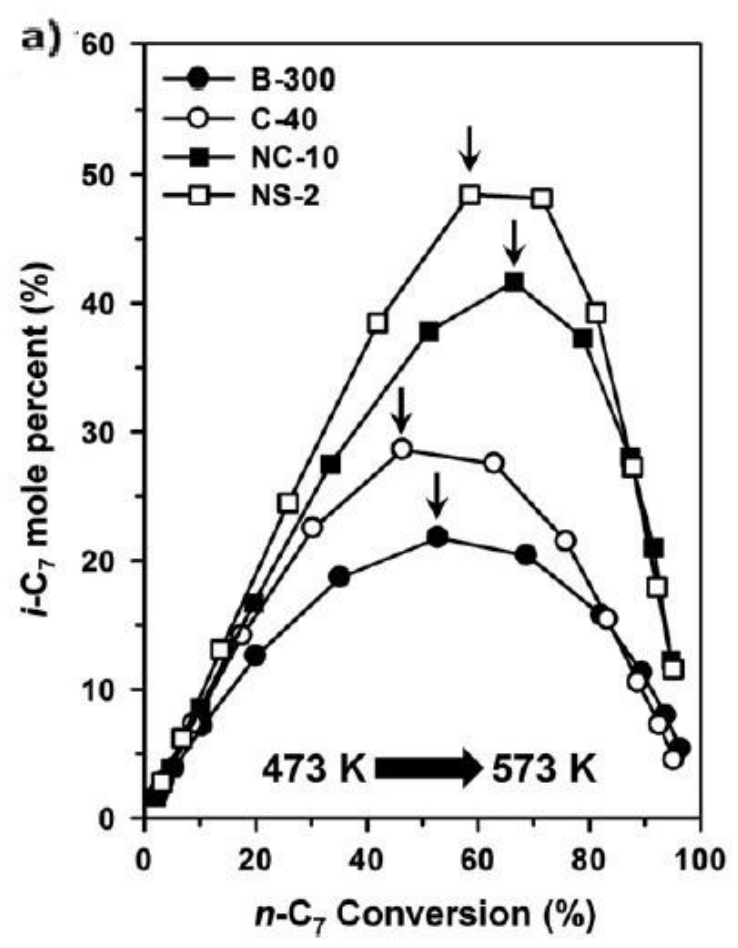




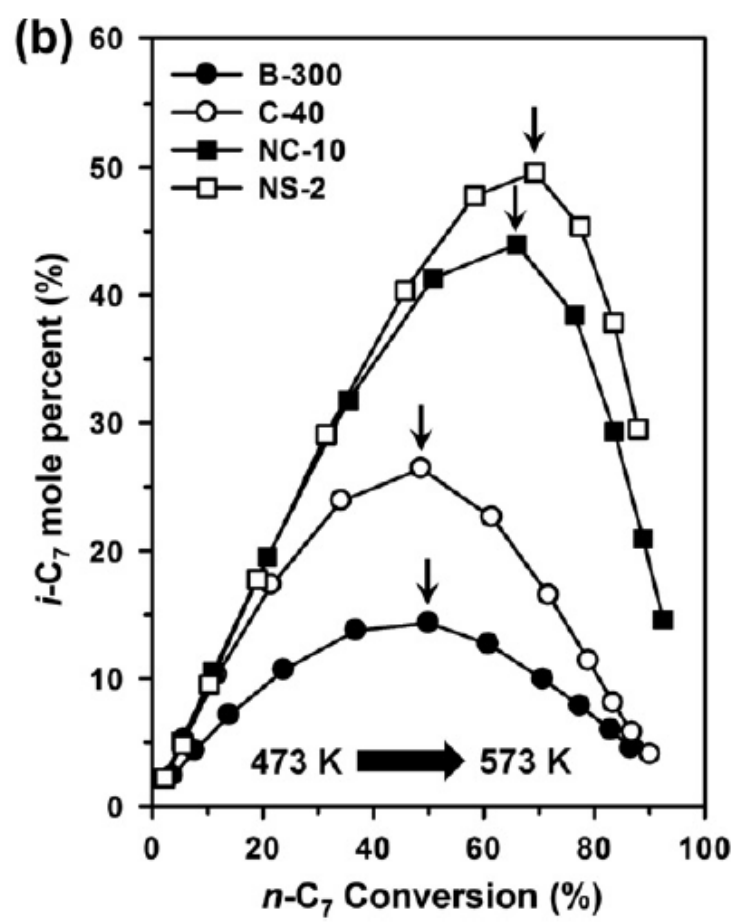

Figure 27. $\mathrm{i}^{-\mathrm{C}_{7}}$ isomer yield (mol\%) versus total $\mathrm{n}-\mathrm{C}_{7}$ conversion by (a) $\mathrm{Pt}(\mathrm{IE}) / \mathrm{MFI}$ and (b) $\mathrm{Pt}(\mathrm{CI}) / \mathrm{MFI}$ catalysts, plotted while increasing reaction temperatures ${ }^{33}$. Reprinted with permission from 33. Copyright 2013 Elsevier.

The increased isomer selectivity of the thin zeolite crystals can be linked to an easier diffusion of the branched isomers inside the zeolite and, consequently, a lower probability of cracking reactions. The micropore opening of MFI zeolite is approx. $0.55 \mathrm{~nm}$, which allows the access of $\mathrm{n}-\mathrm{C}_{7}$ molecules with an approximate molecular size of $0.43 \mathrm{~nm}$. After the isomerization on the acid site, the molecular size of the branched $\mathrm{i}-\mathrm{C}_{7}$ molecules increases to $0.55 \mathrm{~nm}$ causing their diffusion to become hindered. For the larger zeolite crystals, the branched isomers are most likely transformed into the multi-branched isomers and cracked products due to their long residence time inside the zeolite micropores. This results in a decreased yield of the i- $\mathrm{C}_{7}$ products. For the $2 \mathrm{~nm}$ thin nanosheet (NS-2), the primary isomers can easily diffuse out from 
the inside of the zeolite crystal before the cracking reaction occurs, allowing an increased monobranched isomer yield. ${ }^{33}$

Conclusions and Outlook

Bifunctional catalysts play a major role in hydrocracking processes because of the advantages provided by the synergy between metal and acid functions. Their flexibility in product distribution and operating conditions makes them the preferred choice over other alternatives, such as purely monofunctional acid catalysts. In the general hydrocracking mechanism, Brønsted acid sites provide the skeletal isomerization reactions whereas metal sites are responsible for hydrogenation/dehydrogenation (HD/DHD) reactions. Properties such as the balance, the positioning and distance between both functions can have a strong influence on the reaction mechanism, and thus, on the performance of the bifunctional catalyst. An ideal hydrocracking performance is considered to have the skeletal isomerization of alkene intermediates as the ratelimiting step and the HD/DHD reactions under quasi-equilibrium conditions. As a result, consecutive cracking and coking reactions become limited, which leads to upgrades in selectivity, stability and catalyst activity.

The balance of metal and acid sites $\left(\mathrm{n}_{\mathrm{Me}} / \mathrm{n}_{\mathrm{A}}\right)$, and its effect on hydrocracking performance, have typically been investigated by modifying the ratio between both functions. This is usually achieved by adjusting the acid or metal loadings during the preparation of the catalyst. Experiments with varying amounts of acid sites show that both conversion and isomer selectivity are lowered as the amount of acid sites is decreased. This behavior can be explained by an increased separation between bifunctional pairs, caused by a low acid site density and a reduced metal site dispersion. This ultimately raises the cracking probability of branched alkenes. On the other hand, experiments with varying metal loadings indicated that activity is defined by the 
accessibility of the acid sites and an adequate $\mathrm{n}_{\mathrm{Me}} / \mathrm{n}_{\mathrm{A}}$ ratio. Furthermore, isomer selectivity shows an increase with higher values of $n_{M e} / n_{A}$. These trends would suggest that intermediate alkenes undergo HD/DHD more quickly as metal sites become more accessible. However, an excessive metal loading can partially block the pores of the acidic zeolite support, thus hindering the diffusion of intermediates and the subsequent isomerization on acid sites. In contrast, if the metal loading is limited, intermediates are likely to encounter more acid sites during the diffusion step, and undergo successive cracking reactions. Two reaction mechanisms are possible for either low or high $\mathrm{n}_{\mathrm{Me}} / \mathrm{n}_{\mathrm{A}}$ values. A sufficiently high $\mathrm{n}_{\mathrm{Me}} / \mathrm{n}_{\mathrm{A}}$ value is required to avoid the parallel hydrocracking mechanism in favor of a consecutive one, in which intermediates encounter less acid sites during the diffusion step, thus causing cracking reactions to be less likely. Ideally, the average number of acid sites in contact with intermediates during diffusion should be around one.

The separation between metal and acid sites is another factor with a strong influence on the performance of bifunctional catalysts. Throughout the years a proximity criterion was established to determine the necessary distance between sites such that the kinetics do not become hindered by the diffusion of intermediates. In general, this criterion required metal and acid functions to be in the closest possible proximity. However, various authors have recently challenged this notion by experimenting with different scales of distance between sites. Experiments with metalacid site separations at a millimeter scale confirmed a negative impact on catalyst performance. Moreover, under this condition the behavior of the bifunctional catalyst closely resembled the behavior of a monofunctional catalyst. However, experiments with separation lengths within micro- and nanometer scales gave the best performance results, even outperforming smaller separations at an atomic scale. Additional experimental findings have further reinforced this 
challenge to the traditional proximity criterion. These results suggest that a certain degree of separation between metal and acid sites would provide an even better performance compared to having both functions within the closest possible proximity, as long as the transport limitations of the alkene intermediates are mitigated. Specifically, this was achieved by tuning the location of the metal sites, placing them in a mesoporous medium where intermediates can have less transport limitations than in a microporous zeolite. In this scenario, intermediates formed on the metal sites can diffuse more easily towards the mouths of the zeolite's micropores, where they undergo isomerization and then diffuse back to a metal site. This results in reduced cracking and higher isomer yields. If the metal sites were placed inside the micropores of the zeolite, within a closer proximity to their acid counterparts, intermediate molecules would be retained inside the microporous network due to their hindered diffusion. A longer residence time in an acidic environment favors cracking reactions and reduces the selectivity towards isomers. Experiments with different particles sizes and thicknesses of zeolite crystals further support these arguments. It was found that larger particle sizes cause alkene intermediates to experience longer residence times in the zeolite crystals. In contrast, zeolite crystals with a smaller particle size provided less interactions with the acid functions and a higher control of unwanted reactions.

Overall, the recurring trend present in most of the sources gathered in this review seem to prove the important role of transport in the general discussion of bifunctional site intimacy. Not only the distances between metal and acid sites should be considered, but more importantly the nature of the diffusion process undergone by the intermediate molecules should not be ignored. The effect on performance introduced by a lesser degree of proximity can be overcome if the mass transport limitations present between both catalyst functions are reduced. Therefore, a proper balance between the spatial distribution and the material properties that dictate transport 
within the porous structure of the solid catalyst would constitute a more comprehensive approach for defining the intimacy criterion. Moreover, this more novel approach could serve as a better guideline in the tuning or design of bifunctional catalysts with the goal of achieving a more ideal hydrocracking behavior. Given the major importance of hydrocracking in the petrochemical industry, the prospect of bifunctional catalyst optimization is highly valuable for improving refining processes. Considering the expected increase in fuel demands, together with future sustainability targets, the existence of more efficient refining processes would constitute an important step towards attaining sufficient energy accessibility with a reduced environmental impact.

AUTHOR INFORMATION

Corresponding Author

*Tel: +32 (0)9 33117 22. E-mail: Vladimir.Galvita@UGent.be

\section{Author Contributions}

The manuscript was written by Juan I. Mirena. All other authors have contributed to the final version of the manuscript through their discussions.

\section{Funding Sources}

Flemish Research Fund (FWO 3G005417)

\section{ACKNOWLEDGMENT}

The authors would like to express their gratitude to the Flemish Research Fund for their financial support (FWO 3G005417).

\section{ABBREVIATIONS}


BAS, Brønsted acid sites; Bi/M, \% wt ratio of multibranched/monobranched isomer yields; C/I, $\%$ wt ratio of cracking/isomer yields; CI, colloidal impregnation; CPA, anionic hexachloride precursors; DI, dry impregnation; EDX, energy dispersive x-ray; H/C, hydrogen/carbon ratio; HAADF-STEM, high-angle annular dark-field scanning transmission electron microscopy; HD/DHD, hydrogenation/dehydrogenation; IE, ion exchange; IWI, incipient wetness impregnation; LHSV, liquid hourly space velocity; MCM, mobil composition of matter; $\mathrm{MuB} / \mathrm{MB}, \%$ wt ratio of multibranched/monobranched isomer yields; $\mathrm{n}_{\mathrm{Me}} / \mathrm{n}_{\mathrm{A}}$, ratio between the total amount of exposed metal sites and the total amount of acid sites; NPs, nanoparticles; PM, physical mixture; PTA, cationic tetraamine precursors; SAPO, silicoaluminophosphate; SIRAL, silica-alumina hydrates; TOF, turnover frequency; TOS, time on stream; USY, ultrastable Y zeolites; WHSV, weight hourly space velocity; XRD, x-ray diffraction; Y, zeolite Y; ZSM, zeolite socony mobil.

\section{REFERENCES}

1. U.S. Energy Information Administration. International Energy Outlook; U.S. Energy Information Administration: Washington, DC, 2019.

2. Bentley, R. W. Global Oil \& Gas Depletion: An Overview. Energy Policy 2002, 30 (3), 189 205.

3. Speight, J. G. Chapter 10 - Refinery of the Future. In The Refinery of the Future; Speight, J. G., Ed.; William Andrew Publishing, 2011; pp 315-340.

4. Dehkissia, S.; Larachi, F.; Chornet, E. Catalytic (Mo) upgrading of Athabasca bitumen vacuum bottoms via two-step hydrocracking and enhancement of Mo-heavy oil interaction. Fuel 2004, 83 (10), 1323-1331. 
5. Castañeda, L. C.; Muñoz, J. A. D.; Ancheyta, J. Combined process schemes for upgrading of heavy petroleum. Fuel 2012, 100, 110-127.

6. Speight, J. G. Chapter 21: Hydrocracking. In The Chemistry and Technology of Petroleum; CRC Press: Boca Raton, 2011; pp 634-672.

7. Paris, C.; Moliner, M.; Corma, A. Metal-containing zeolites as efficient cataysts for the transformation of highly valuable chiral biomass-derived products. Green Chem. 2013, 15 (8), 2101-2109.

8. Regali, F.; Boutonnet, M.; Järås, S. Hydrocracking of n-hexadecane on noble metal/silicaalumina catalysts. Catal. Today 2013, 214, 12-18.

9. Korre, S. C.; Klein, M. T.; Quann, R. J. Hydrocracking of polynuclear aromatic hydrocarbons. Development of rate laws through inhibition studies. Ind. Eng. Chem. Res. 1997, $36(6), 2041-2050$.

10. Speight, J. G. New approaches to hydroprocessing. Catal. Today 2004, 98 (1-2), 55-60.

11. Scherzer, J.; Gruia, A. J. Hydrocracking science and technology; CRC Press: New york, 1996.

12. Thybaut, J. W.; Laxmi Narasimhan, C. S.; Denayer, J. F.; Baron, G. V.; Jacobs, P. A.; Martens, J. A.; Marin, G. B. Acid-metal balance of a hydrocracking catalyst: Ideal versus nonideal behavior. Ind. Eng. Chem. Res. 2005, 44 (14), 5159-5169.

13. Fahim, M. A.; Al-Sahhaf, T. A.; Elkilani, A. Chapter 7: Hydroconversion. in Fundamentals of Petroleum Refining; Elsevier, 2009.

14. Chekantsev, N. V.; Gyngazova, M. S.; Ivanchina, E. D. Mathematical modeling of light naphtha $\left(\mathrm{C}_{5}, \mathrm{C}_{6}\right)$ isomerization process. Chem. Eng. J. 2014, 238, 120-128. 
15. van Veen, J. A. R.; Minderhoud, J. K.; Huve, L. G.; Stork, W. H. J. in Handbook of Heterogeneous Catalysis; Ertl, G., Knözinger, H., Weitkamp, J., Schüth, F., Eds.; WileyVCH, 2008; Vol. 6, pp 2778-2808.

16. Marcilly, C. Acid-Basic Catalysis: Application to Refining and Petrochemistry; IFP Publications: Paris, 2006.

17. Weisz, P. B. Polyfunctional heterogeneous catalysis. Adv. Catal. 1962, 13, 137-193.

18. Ertl, G.; Knözinger, H.; Weitkamp, J. Preparation of solid catalysts; Wiley-VCH: Weinheim, 1999.

19. Cam, L. L.; Nguyen, T.; Kim, T. D. T.; Gaidai, N. A.; Agafonov, Y. A.; Cam, A. H.; Cuong, H. T.; Lapidus, A. L. Kinetics of n-hexane isomerization over supported palladium catalysts. Kinet. Catal. 2017, 58 (3), 311-320.

20. Guisnet, M.; Gilson, J. P. Zeolites for cleaner technologies; Imperial College Press: London, 2002.

21. Sinfelt, J. H. Bifunctional Catalysis. Adv. Chem. Eng. 1964, 5, 37-74.

22. Samad, J. E.; Blanchard, J.; Sayag, C.; Louis, C.; Regalbuto, J. R. The controlled synthesis of metal-acid bifunctional catalysts: The effect of metal-acid ratio and metal-acid proximity in Pt silica-alumina catalysts for n-heptane isomerization. J. Catal. 2016, 342, 203-212.

23. McVicker, G. B.; Daage, M.; Touvelle, M. S.; Hudson, C. W.; Klein, D. P.; Baird Jr, W. C.; Cook, B. R.; Chen, J. G.; Hantzer, S.; Vaughan, D. E. W.; Ellis, E. S.; Feelay, O. C. Selective ring opening of naphthenic molecules. J. Catal. 2002, 210 (1), 137-148.

24. Monteiro, C. A.; Costa, D.; Zotin, J. L.; Cardoso, D. Effect of metal-acid site balance on hydroconversion of decalin over Pt/Beta zeolite bifunctional catalysts. Fuel 2015, 160, 71- 
79.

25. Anaya, F.; Zhang, L.; Tan, Q.; Resasco, D. E. Tuning the acid-metal balance in Pd/and $\mathrm{Pt} /$ zeolite catalysts for the hydroalkylation of m-cresol. J. Catal. 2015, 328, 173-185.

26. Weitkamp, J. Catalytic hydrocracking-mechanisms and versatility of the process. ChemCatChem 2012, 4 (3), 292-306.

27. Coonradt, H. L.; Garwood, W. E. Mechanism of hydrocracking. Reactions of Paraffins and Olefins. Ind. Eng. Chem. Process Des. Dev. 1964, 3 (1), 38-45.

28. Guisnet, M. “Ideal” bifunctional catalysis over Pt-acid zeolites. Catal. Today 2013, 218, 123134.

29. Guisnet, M. Catalysis on bifunctional Pt acid zeolites. A route to cleaner processes. Pol. J. Chem. 2003, 77 (6), 637-656.

30. Hölderich, W. F. New Aspects in the Performance of Heterogeneous Catalysts for Intermediates and Fine Chemicals. Heterogeneous Catalysis and Fine Chemicals 1988, 41, 83-90.

31. Mendes, P. S.; Silva, J. M.; Ribeiro, M. F.; Daudin, A.; Bouchy, C. Synergies, cooperation and other effects: a review for hydroconversion catalysts. Catal. Today 2020, 356, 260-270.

32. Wang, W.; Liu, C. J.; Wu, W. Bifunctional catalysts for the hydroisomerization of n-alkanes: the effects of metal-acid balance and textural structure. Catal. Sci. Techol. 2019, 9, 41624187.

33. Kim, J.; Kim, W.; Seo, Y.; Kim, J. C.; Ryoo, R. n-Heptane hydroisomerization over Pt/MFI zeolite nanosheets: Effects of zeolite crystal thickness and platinum location. J. Catal. 2013, 301, 187-197. 
34. Mendes, P. S.; Silva, J. M.; Ribeiro, M. F.; Daudin, A.; Bouchy, C. From powder to extrudate zeolite-based bifunctional hydroisomerization catalysts: on preserving zeolite integrity and optimizing Pt location. J. Ind. Eng. Chem. 2018, 62, 72-83.

35. Sánchez, P.; Dorado, F.; Ramos, M. J.; Romero, R.; Jiménez, V.; Valverde, J. L. Hydroisomerization of C6-C8 n-alkanes, cyclohexane and benzene over palladium and platinum beta catalysts agglomerated with bentonite. Appl. Catal. A: Gen. 2006, 314 (2), 248-255.

36. Ali, M. A.; Tatsumi, T.; Masuda, T. Development of heavy oil hydrocracking catalysts using amorphous silica-alumina and zeolites as catalyst supports. Appl. Catal. A: Gen. 2002, 233 (1-2), 77-90.

37. Deldari, H. Suitable catalysts for hydroisomerization of long-chain normal paraffins. Appl. Catal. A: Gen. 2005, 293, 1-10.

38. Corma, A.; Martínez, A. Zeolites in refining and petrochemistry. Stud. Surf. Sci. Catal 2005, 157, 337-366.

39. Akhmedov, V. M.; Al-Khowaiter, S. H. Recent Advances and Future Aspects in the Selective Isomerization of High n-Alkanes. Cat. Rev. Sci. Eng. 2007, 49 (1), 33-139.

40. Martens, G. G.; Marin, G. B.; Martens, J. A.; Jacobs, P. A.; Baron, G. V. A fundamental kinetic model for hydrocracking of $\mathrm{C} 8$ to $\mathrm{C} 12$ alkanes on Pt/US-Y zeolites. J. Catal. 2000, 195 (2), 253-267.

41. Batalha, N.; Pinard, L.; Bouchy, C.; Guillon, E.; Guisnet, M. n-Hexadecane hydroisomerization over Pt-HBEA catalysts. Quantification and effect of the intimacy between metal and protonic sites. J. Catal. 2013, 307, 122-131. 
42. Mendes, P. S.; Silva, J. M.; Ribeiro, M. F.; Duchêne, P.; Daudin, A.; Bouchy, C. Quantification of metal-acid balance in hydroisomerization catalysts: A step further toward catalyst design. AIChE J. 2017, 63 (7), 2864-2875.

43. Henry, R.; Tayakout-Fayolle, M.; Afanasiev, P.; Lorentz, C.; Lapisardi, G.; Pirngruber, G. Vacuum gas oil hydrocracking performance of bifunctional Mo/Y zeolite catalysts in a semibatch reactor. Catal. Today 2014, 220, 159-167.

44. Ward, J. W. Hydrocracking processes and catalysts. Fuel Process. Technol. 1993, 35 (1-2), 55-85.

45. Musselwhite, N.; Na, K.; Sabyrov, K.; Alayoglu, S.; Somorjai, G. A. Mesoporous aluminosilicate catalysts for the selective isomerization of n-Hexane: the roles of surface acidity and platinum metal. J. Am. Chem. Soc. 2015, 137 (32), 10231-10237.

46. Scott, J. W.; Bridge, A. G. The continuing development of hydrocracking. Adv. Chem. 1971, 103, 113-129.

47. Ben Moussa, O.; Tinat, L.; Jin, X.; Baaziz, W.; Durupthy, O.; Sayag, C.; Blanchard, J. Heteroaggregation and Selective Deposition for the Fine Design of Nanoarchitectured Bifunctional Catalysts: Application to Hydroisomerization. ACS Catal. 2018, 8 (7), 60716078.

48. Zhang, J.; Wu, H.; Zhao, A.; Bai, X.; Kikhtyanin, O. V.; Wu, W.; Zhang, R. Synthesis of MgAPO-31 nanocrystals via different heating methods and their catalytic performance in the hydroisomerization of n-decane. J. Porous Mater. 2016, 24 (2), 437-442.

49. Weitkamp, J.; Ernst., S. Factors influencing the selectivity of hydrocracking in zeolites. In Guidelines for mastering the properties of molecular sieve; Plenum Press: New York, 1990; 
pp 343-354.

50. Francis, J.; Guillon, E.; Bats, N.; Pichon, C.; Corma, A.; Simon, L. J. Design of improved hydrocracking catalysts by increasing the proximity between acid and metallic sites. App. Catal. A: Gen. 2011, 409-410, 140-147.

51. Wei, X.; Kikhtyanin, O. V.; Parmon, V. N.; Wu, W.; Bai, X.; Zhang, J.; Xiao, L.; Su, X.; Zhang, Y. Synergetic effect between the metal and acid sites of Pd/SAPO-41 bifunctional catalysts in n-hexadecane hydroisomerization. J. Porous Mater. 2018, 25 (1), 235-247.

52. Zhang, Y.; Wang, W.; Jiang, X.; Su, X.; Kikhtyanin, O. V.; Wu, W. Hydroisomerization of n-hexadecane over a Pd-Ni2P/SAPO-31 bifunctional catalyst: synergistic effects of bimetallic active sites. Catal. Sci. Technol. 2018, 8, 817-828.

53. Alvarez, F.; Ribeiro, F. R.; Perot, G.; Thomazeau, Y. C.; Guisnet, M. Hydroisomerization and Hydrocracking of Alkanes: 7. Influence of the Balance between Acid and Hydrogenating Functions on the Transformation ofn-Decane on PtHY Catalysts. J. Catal. 1996, 162 (2), 179-189.

54. de Lucas, A.; Sánchez, P.; Dorado, F.; Ramos, M. J.; Valverde, J. L. Effect of the metal loading in the hydroisomerization of n-octane over beta agglomerated zeolite based catalysts. App. Catal. A: Gen. 2005, 294 (2), 215-225.

55. Batalha, N.; Pinard, L.; Pouilloux, Y.; Guisnet, M. Bifunctional hydrogenating/acid catalysis: quantification of the intimacy criterion. Catal. Lett. 2013, 143 (6), 587-591.

56. Gutierrez-Acebo, E.; Leroux, C.; Chizallet, C.; Schuurman, Y.; Bouchy, C. Metal/acid bifunctional catalysis and intimacy criterion for ethylcyclohexane hydroconversion: when proximity does not matter. ACS Catal. 2018, 8 (7), 6035-6046. 
57. Zečević, J.; Vanbutsele, G.; de Jong, K. P.; Martens, J. A. Nanoscale intimacy in bifunctional catalysts for selective conversion of hydrocarbons. Nature 2015, 528, 245.

58. Rivallan, M.; Seguin, E.; Thomas, S.; Lepage, M.; Takagi, N.; Hirata, H.; Thibault-Starzyk, F. Platinum Sintering on H-ZSM-5 Followed by Chemometrics of CO Adsorption and 2D Pressure-Jump IR Spectroscopy of Adsorbed Species. Angew. Chem. Int. Ed. Engl. 2010, 49 (4), 785-789.

59. Lv, G.; Wang, C.; Chi, K.; Liu, H.; Wang, P.; Ma, H.; Wei, Q.; Tian, Z. Effects of Pt site distributions on the catalytic performance of Pt/SAPO-11 for n-dodecane hydroisomerization. Catal. Today 2018, 316, 43-50.

60. Somorjai, G. A.; Park, J. Y. Colloid science of metal nanoparticle catalysts in 2D and 3D structures. Challenges of nucleation, growth, composition, particle shape, size control and their influence on activity and selectivity. Top. Catal. 2008, 49, 126-135.

61. Zhao, Y.; Jia, L.; Medrano, J. A.; Ross, J. R. . \&. L. L. Supported Pd catalysts prepared via colloidal method: the effect of acids. ACS Catal. 2013, 3 (10), 2341-2352.

62. Thybaut, J. W.; Marin, G. B. Multiscale aspects in hydrocracking: from reaction mechanism over catalysts to kinetics and industrial application. Adv. Catal. 2016, 59, 109-238.

63. Li, M.; Zhang, Y.; Wang, H.; Yu, S.; Liu, D.; Wang, Y. Influence of zeolite crystal size on selective conversion of n-alkane: Controlling intermediates' diffusion distances inside the micropores. Fuel 2019, 254, 115709.

64. Tao, Y.; Kanoh, H.; Abrams, L.; Kaneko, K. Mesopore-modified zeolites: preparation, characterization, and applications. Chem. Rev. 2006, 106 (3), 896-910.

65. Lima, P. M.; Garetto, T.; Cavalcante Jr, C. L.; Cardoso, D. Isomerization of n-hexane on Pt- 
Ni catalysts supported on nanocrystalline H-BEA zeolite. Catal. Today 2011, 172 (1), 195202.

66. Zhang, Y.; Liu, D.; Men, Z.; Huang, K.; Lv, Y.; Li, M.; Lou, B. Hydroisomerization of ndodecane over bi-porous Pt-containing bifunctional catalysts: Effects of alkene intermediates' journey distances within the zeolite micropores. Fuel 2019, No. 236, 428-436.

67. Kresge, C. T.; Leonowicz, M. E.; Roth, W. J.; Vartuli, J. C.; Beck, J. S. Ordered mesoporous molecular sieves synthesized by a liquid-crystal template mechanism. Nature 1992, 359, 710712.

68. Park, K. C.; Ihm, S. K. Comparison of Pt/zeolite catalysts for n-hexadecane hydroisomerization. Appl. Catal. A: Gen. 2000, 203 (2), 201-209.

69. Zhang, Y.; Liu, Y.; Li, Y. Synthesis and characteristics of Y-zeolite/MCM-48 biporous molecular sieve. Appl. Catal. A: Gen. 2008, 345 (1), 73-79.

70. Vu, X. H.; Armbruster, U.; Martin, A. Micro/mesoporous zeolitic composites: Recent developments in synthesis and catalytic applications. Catalysts 2016, 6 (12), 183.

71. Liu, X.; Yang, T.; Bai, P.; Han, L. Y/MCM-41 composites assembled from nanocrystals. Microporous Mesoporous Mater. 2013, 181, 116-122.

72. Christensen, C. H.; Schmidt, I.; Christensen, C. H. Improved performance of mesoporous zeolite single crystals in catalytic cracking and isomerization of n-hexadecane. Catal. Commun. 2004, 5 (9), 543-546. 


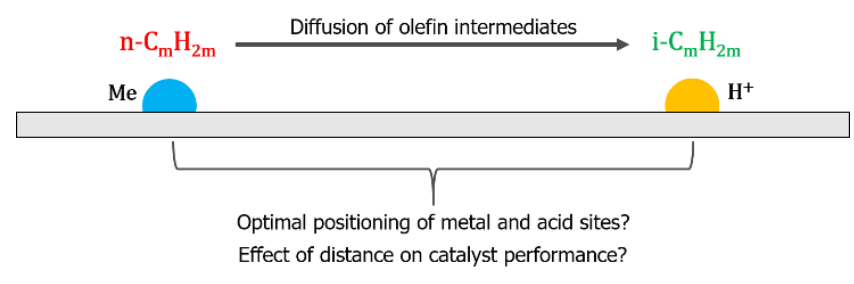

For Table of Contents Only 